\title{
Decompression nerve surgery for diabetic neuropathy: a structured review of published clinical trials
}

This article was published in the following Dove Press journal: Diabetes, Metabolic Syndrome and Obesity:Targets and Therapy

\author{
James W Albers' \\ Ryan Jacobson ${ }^{2}$ \\ 'Department of Neurology, University \\ of Michigan Medical School, Ann \\ Arbor, MI, USA; ${ }^{2}$ Department of \\ Neurology, Rush University Medical \\ Center, Chicago, IL, USA
}

Aim: To assess lower extremity decompression nerve surgery (DNS) to treat the consequences of diabetic distal symmetric peripheral neuropathy (DPN).

Research design and methods: MEDLINE, PubMed, and related registries were searched through December 2017 to identify randomized, quasi-randomized or observational trials that evaluated the efficacy of lower extremity DNS on pain relief (primary outcome) or other secondary outcomes. Observational studies were included, given investigators' reluctance to use sham surgery controls. Outcome effect size was estimated, and a weighted average was calculated. Results: Eight of 23 studies evaluated pain relief, including a double-blind randomized controlled trial (with a sham surgery leg), an unblinded trial with a nonsurgical control leg, and 6 observational studies. All reported substantial pain relief post-DNS with average effect sizes between two and five. Unexpectedly, the double-blind trial showed improvement in the sham leg comparable to the DNS leg and exceeding the improvement observed in the nonsurgical leg in the unblinded study. Sensory testing showed generally favorable results supporting DNS, and nerve conduction velocities increased post-DNS relative to deterioration in controls. Ultrasound revealed fusiform nerve swelling near compression sites. Morphological results of DNS were generally favorable but inconsistent, whereas hemodynamic measures showed a positive effect on arterial parameters, as did transcutaneous oximetry (improved microcirculation). The incidence of initial and recurrent neuropathic diabetic foot ulcers appeared reduced post-DNS relative to the contralateral foot (borderline significant).

Conclusion: The data remain insufficient to recommend DNS for painful DPN, given conflicting and unexpectedly positive results involving sham surgery relative to unblinded controls. The generally supportive sensory and nerve conduction results are compromised by methodological issues, whereas more favorable results support DNS to prevent new or recurrent neuropathic foot ulcers. Future studies need to clarify subject selection vis-à-vis DPN vs superimposed compressed nerves, utilize appropriate validated instruments, and readdress use of sham surgical controls in light of recent results.

Keywords: diabetic neuropathy, painful neuropathy, neuropathy treatment

\section{Introduction}

Diabetic neuropathy in its most typical form is a distal symmetric peripheral neuropathy (diabetic peripheral neuropathy [DPN]). This dying-back length-dependent neuropathy is a common source of morbidity, disability, and reduced quality of life. A subset of patients with a DPN experience painful prickling, stabbing, and burning sensations that likely reflect small-fiber involvement and ultimately result in persistent neuropathic pain affecting about $20 \%$ of diabetic patients. ${ }^{1}$ The mechanisms producing DPN are
Correspondence: James W Albers University of Michigan Medical School, 1500 E. Medical Center Drive, UH South F2647, Ann Arbor, MI 48109, USA

Tel +l 7349368586

Fax +I 7349365185

Email jwalbers@umich.edu 
undoubtedly multifactorial, and at present, the only proven treatment shown to effectively delay the onset or progression of DPN is intensive glycemic control. ${ }^{2}$

In the last decade, several attempts have been made to evaluate the utility of decompression nerve surgery (DNS) in patients with diabetes, especially those with a painful DPN. In 2006, the American Academy of Neurology (AAN) issued a practice advisory, summarizing their review of eleven studies. ${ }^{3}$ All were considered Class IV evidence (uncontrolled studies, case series, case reports, or expert opinions). The authors emphasized that no studies relied on typical bedside neurological testing, and noted that it was unclear to what extent the reported benefits relate to the release of focally compressed nerves or a treatment of DPN. In 2007, Dellon reviewed 15 studies. ${ }^{4}$ In each, diabetic patients had symptomatic DPN, no history of ulceration or amputation, and a positive Tinel sign at the tarsal tunnel, a sign purported to demonstrate the site of compression and suggesting the surgery was performed to release a compressed nerve as opposed to the treatment of a diffuse DPN. He noted reduced pain and improved sensation in the majority of DNS intervention subjects. No patient who underwent surgery developed an incident diabetic foot ulcer (DFU), and the rate of ulceration in patients with previous ulcers was lower than expected. Overall, he concluded that pain and restoration of sensation can be expected in about $80 \%$ of patients with DPN who undergo DNS.

In 2008, a Cochrane review addressed the utility of lower limb DNS in DPN. ${ }^{5}$ The primary outcome measure was the magnitude of the change in pain as measured by a visual analog scale (VAS). Ultimately, only one of eight studies investigated used a VAS as a primary endpoint and no randomized trials were available for inclusion. The role of DNS was deemed unproven. Baltodano et al reviewed the effects of lower extremity DNS in diabetics in $2013 .{ }^{6}$ This group focused on those patients with lower extremity nerve compression, and ten studies were included. Most studies relied on a positive Tinel sign to diagnose nerve compression, but three relied on nerve conduction study (NCS) results. Benefits with regards to pain, sensibility, and risk of ulceration were noted. The authors highlighted that inclusion of only those studies examining patients with compressed nerves strengthened their meta-analysis.

Tu et al reviewed the impact of DNS in 2016, taking into account both upper extremity (carpal tunnel) procedures and lower extremity decompression. ${ }^{7}$ Two studies each looked at VAS and two-point sensory discrimination in the lower extremities, and pooled analyses demonstrated a benefit in both outcomes. Lower extremity decompression was thought to be effective based on these data. Also, in 2016, Tannemaat et al discussed the current state of the literature. ${ }^{8}$ They noted that all studies were observational and there was no proven benefit to DNS. They suggested the possibility of a doubleblinded study employing both nerve decompression and contralateral sham surgery.

Many consider the use of DNS to treat DPN as unproven., Proponents view the surgery as a promising therapy for properly selected cases of DPN, noting that unproven is not equivalent to unnecessary and unnecessary does not equate to ineffective or harmful. ${ }^{9}$ Despite evidence, much of which is widely acknowledged as inadequate to justify DNS to treat painful DPN, the procedure continues to be performed. The objective of our review was to extend previous structured reviews to identify interval clinical studies describing the use of DNS to treat the consequences of DPN. The consequences we evaluated included pain (primary outcome), as well as sensation, nerve function (electrophysiology, morphology, and hemodynamics), and the incidence of initial and recurrent neuropathic DFUs (all secondary outcomes). We also hoped to clarify the evaluation criteria important to the selection of DNS candidates.

\section{Research design and methods}

We included published human studies in which the efficacy of DNS was used to alleviate or prevent symptoms, signs, or other adverse consequences of DPN. At times, it remained unclear if subjects were included who had compressive mononeuropathies superimposed on a DPN. Our initial intent was to review only randomized or quasi-randomized-controlled trials, but we expanded our search to all cohort trials. We defined cohort studies according to Strengthening the Reporting of Observational Studies in Epidemiology guidelines to include any trials in which participants underwent a common exposure (DNS) and were followed over time. ${ }^{10}$

\section{Electronic searches}

We searched MEDLINE, PubMed (which includes PreMEDLINE), ArticlesPlus, EMBASE, CENTRAL (Cochrane Library), PUBMED, LILACS, SCOPUS, and Google Scholar through December 2017 to identify citations involving lower extremity DNS or neurolysis and DPN. The searches were based on the following search strategy: 1) diabetes mellitus, diabetic neuropathies, diabetic peripheral neuropathy, diabetic polyneuropathy, or diabetic foot AND 2) treatment with DNS, surgical decompression, or neurolysis. The titles and abstracts of the resulting articles were reviewed to identify 
those potentially relevant. Those articles were obtained, and their bibliographies reviewed to identify additional articles. Our search was restricted by language to the extent that English abstracts were required. In a few instances, we contacted the trial authors for additional information. An example of the electronic search strategy (MEDLINE) is attached as Supplementary material.

\section{Participants}

We included adult participants of either sex with type 1 or type 2 diabetes undergoing DNS for some consequence of a DPN. The DPN could be painful or non-painful, although relief of pain attributed to a DPN was the primary outcome of interest. DFUs had to be attributed to the DPN (neuropathic DFUs), not to vascular disease.

\section{Interventions}

We included all relevant articles describing DNS in one or both legs. DNS involved decompression of all, one, or some combination of the following nerves: 1) common peroneal (fibular) nerve (at the fibular neck), 2) deep peroneal (fibular) nerve (at the dorsum of the foot), and 3 ) tibial nerve (at the lateral ankle) and its medial plantar, lateral plantar, and calcaneal branches (at the foot) (the four medial ankle tunnels). Decompression of the common peroneal, deep peroneal, and the four medial ankle tunnels, with or without internal neurolysis depending on the intraoperative observation of scar tissue formation, is often referred to as the "Dellon technique", in recognition of his pioneering work involving this procedure.

\section{Outcome measures}

The primary outcome measure was change in pain, as measured by a global subjective outcome scale. We included pain scores using a VAS (eg, an 11-point scale ranging from 0 being "no perceptible pain" to 10 being "intolerable pain") or a Likert scale, as the results show significant correlation and similar validity. ${ }^{11}$ We were interested in early and late results after DNS, and all outcomes were considered during any interval after surgery from days to 60 months. When multiple intervals were reported, the ones nearest to 3 months (early) and 18 months (late) were selected for the primary pain measure.

Secondary outcome measures included quantitative or semi-quantitative sensory test results; NCS results (sensory or motor response amplitude, conduction velocity [CV], or distal latency); ultrasonography (US) nerve caliber measurements, microcirculation evaluations, and development of initial or recurrent neuropathic DFUs or amputations (studies involving patients with diabetic peripheral vascular disease were excluded). The sensory measures potentially included tests of two-point discrimination (2PD; foot), touch-pressure (eg, using Semmes Weinstein monofilaments), or vibration sensation (great toe).

\section{Study selection}

Each paper was classified by study type to identify all randomized or quasi-randomized-controlled trials or observational case series. Given the reluctance of some investigators to include a sham surgical control, and ignoring the ethical controversy surrounding such trials, we included results from controlled studies that were not randomized or blinded. We defined cohort studies to include any trials in which patients underwent a common exposure (eg, DNS for DPN) and were followed over time..$^{10,12,13}$ Using this definition, a comparison group was not required, although many studies performed DNS on one side and used the contralateral limb as a control. ${ }^{14}$ Both authors evaluated studies for eligibility, serially abstracted data, and independently evaluated risk bias. The selected studies are summarized in Table 1.

\section{Data extraction and management}

Both authors assessed each study. Data extraction was performed by one author and confirmed by the other. A consensus was obtained for any discrepancies.

\section{Assessment of risk bias}

Risk bias was assessed using validated means of risk assessment that included the Delphi list score $(0-9)^{15,16}$ (Table 1) and the Cochrane tool ${ }^{17}$ for randomized studies (Table 2).

\section{Data synthesis and analysis}

Few studies using paired samples or repeated measures provided the raw data or the paired sample correlations, and several used analyses that assumed independent samples. These problems and differences in methodologies made it difficult in most cases to combine the results and assess the statistical significance of pre- and post-DNS changes. Because of these obstacles, we estimated the effect size (standardized mean difference) for common outcomes as an index that could be compared across studies. When the paired-sample $t$-statistic or correlation between repeated measures was unavailable, we used several methods to estimate the effect size, including Hedge's $g$ for paired samples or procedures suggested by Morris and DeShon $(2008)^{20}$ or incorporated in R (MBESS), in which case the $r$ values were estimated using results 
Table I Characteristics of studies of lower extremity DNS for diabetic peripheral neuropathy

\section{Author (year)
Study type; setting; study length; Delphi score $(0-9)^{16}$}

Aszmann et al (2000) $)^{34,37}$ (duplicates)

Prospective, consecutive, unblinded, contralateral limb control; single-center; follow-up $\geq 12$ months (mean: 23.3); Delphi score: 3

Aszmann et al (2004) $)^{50}$

Retrospective, contralateral limb control; single-center; follow-up $\geq 24$ months (mean:

54); Delphi score: 2

Dellon (1992) ${ }^{41}$

Prospective, consecutive, unblinded, contralateral limb control (some); singlecenter; follow-up $\geq 6$ months (mean: 30 );

Delphi score: 2

Dellon $(2012)^{25,84}$

Prospective, consecutive, unblinded; multicenter; follow-up every 6 months up to 3.5 years (all $\geq 12$ months); Delphi score: 2 Karagoz (2008) ${ }^{26}$

Prospective, consecutive, unblinded; singlecenter; follow-up PO day I and $\geq 6$ months (mean: 8); Delphi score: I

Knobloch (2012 abstract) ${ }^{27}$

Prospective, consecutive, unblinded; singlecenter; follow-up $\geq 6$ months (mean: I2);

Delphi score: $2 / 9$

Lee and Dellon (2004) ${ }^{85}$

Prospective, cross-sectional, consecutive, unblinded; single-center, follow-up 12 months;

Delphi score: 2

Liao $(2104)^{28}$

Retrospective; single-center (Xinhua); followup every 6 months for 24 months; Delphi score: 4

Macaré van Maurik (2015) ${ }^{33}$

Prospective, consecutive, randomized (surgical side, contralateral limb control), unblinded;

single-center; follow-up 3, 6, 12 months;

Delphi score: 5

Macaré van Maurik (2015) ${ }^{42}$

Same; follow-up 12 months

Macaré van Maurik (2014) ${ }^{31}$

Same; follow-up mean 28 weeks (23-45

weeks); Delphi score: 4

Macaré van Maurik (2015) ${ }^{66}$

Same; follow-up 6 and 12 months; Delphi

score: 4

Nickerson $^{46,86}$

Retrospective; single-center; follow-up 2.5

(I-I3) years, extended follow-up additional 3 years, ${ }^{86}$

Delphi score: 3

\section{Participants}

TIDM ( $n=14)$ or T2DM

$(\mathrm{n}=6)$; painful DPN; +Tinel

(ankle or over other nerves

decompressed)

Intervention

Outcome(s)

\section{TIDM or T2DM ( $n=50)$; DPN}

DNS tibial (ankle); 6 of 20 had Sensation: 2PD

bilateral surgery; ( 8 subjects

had DNS of median and/or

ulnar nerves)
TIDM $(n=38)$ or T2DM $(n=22)$; symptomatic DPN (exclusive

burning pain excluded); +Tinel

DM ( $n=628,465$ painful)

(described limbs, not cases);

DNS peroneal (knee); deep

peroneal (foot); four tibial

DNS of peroneal (14); deep

peroneal (I2); tibial (3I)

bilateral DNS

TIDM ( $n=16)$ or T2DM ( $n=8)$; $\quad$ DNS peroneal (knee); deep

symptomatic DPN (20/24 painful; peroneal (foot); four tibial I2/24 ulcers)

$\operatorname{DM}(n=12)$; DPN

DM ( $n=46)$; symptomatic DPN, compared + or - Tinel (ankle)

DM ( $n=306)$; painful DPN, focal pain $(n=145)$ or diffuse pain

(16I); +Tinel

Controls $(n=92)$

$\operatorname{TIDM}(n=8)$ or T2DM $(n=30)$;

painful DPN; +Tinel (I7\% of

subjects had baseline 2PD)

$\operatorname{TIDM}(n=10)$ or T2DM $(n=30) ; \quad$ Same

painful DPN;+ Tinel

$\operatorname{TIDM}(n=10)$ or T2DM $(n=32) ; \quad$ Same

painful DPN;+ Tinel; $A B I$

$0.8-1.15 ; \mathrm{TBI} \geq 0.7 ;+\mathrm{PT}$ and DP

pulses

Controls $(n=38)$

TIDM or T2DM $(n=39)$ painful Same

DPN;+ Tinel

DM ( $\mathrm{n}=65$ cases, 75 legs); DPN with previous/current ulcer; previous DNS for ulcer or neuropathic pain; palpable pulses tunnels (ankle)

DNS peroneal (knee); deep peroneal (foot); four tibial tunnels (ankle) tunnels (ankle)

DNS peroneal (knee); deep peroneal (foot); four tibial

DNS peroneal (knee); deep peroneal (foot); four tibial tunnels (ankle)

DNS peroneal (knee); deep peroneal (foot); four tibial tunnels (ankle)

DNS unilateral peroneal (knee); deep peroneal (foot); four tibial tunnels (ankle)
DNS peroneal (knee); deep

peroneal (foot); four tibial

tunnels

Ulcer or amputation

Sensation: descriptive 2PD NCS (performed on $70 \%$ of nerves)

\section{Pain: VAS}

Ulcer: new or recurrent

Sensation: T-P, 2PD

Pain: VAS

Sensation: 2PD

Pain: VAS

Ulcer: new or recurrent

Sensation: (Likert)

Balance: (Likert)

Subjective based on interview and sensation: good/excellent or poor/failure

Pain: VAS, BPI

Sensation: 2PD

NCS: TMA, PMA, SPA, SSC

(CV)

High-resolution US: tibial CSA

Pain: VAS

Sensation: T-P, 2PD

NCS: TMA, PMA, PMAT

(amplitude, CV, distal latency)

US: CSA tibial nerve; thickness

of flexor retinaculum

Stability: quantitative sway; eyes open and closed

Ulcer: new or recurrent 
Table I (Continued)

\begin{tabular}{|c|c|c|c|}
\hline $\begin{array}{l}\text { Author (year) } \\
\text { Study type; setting; study length; Delphi } \\
\text { score }(0-9)^{16}\end{array}$ & Participants & Intervention & Outcome(s) \\
\hline $\begin{array}{l}\text { Nickerson }(2014)^{49} \\
\text { Retrospective; multicenter; subset prospective } \\
\text { cohort; follow-up I and } 3 \text { years; Delphi score: } 3\end{array}$ & $\begin{array}{l}\text { Subset of above with painful } \\
\text { DPN }(n=42), \geq \text { I ulcer healed; } \\
+ \text { Tinel, } \geq \text { I pulse, or } A B I>0.8\end{array}$ & Same & $\begin{array}{l}\text { Ulcer: recurrent ipsilateral vs } \\
\text { new ulcer contralateral control } \\
\text { leg }\end{array}$ \\
\hline $\begin{array}{l}\text { Rader }(2005)^{29} \\
\text { Prospective, consecutive, sensory technician } \\
\text { blinded; single-center; follow-up } 3 \text { and } 6 \\
\text { months; Delphi score: } 3\end{array}$ & $\begin{array}{l}\text { TIDM }(n=7) \text { or T2DM }(n=32) \\
\text { DM; ( } 39 \text { cases, } 49 \text { legs); painful } \\
\text { DPN or ulceration strongly + } \\
\text { Tinel }\end{array}$ & $\begin{array}{l}\text { DNS peroneal (knee); deep } \\
\text { peroneal (foot); four tibial } \\
\text { tunnels (ankle) } \pm \text { neurolysis; } 10 \\
\text { of } 39 \text { bilateral surgery }\end{array}$ & $\begin{array}{l}\text { Pain: VAS } \\
\text { Sensation: T-P, 2PD }\end{array}$ \\
\hline $\begin{array}{l}\text { Rozen et al ( } 2017 \text { abstract only) } \\
\text { Prospective, consecutive, randomized ( } 2: \mathrm{I} \\
\text { surgery [DNS vs sham] vs control), blinded } \\
\text { subjects and evaluators; multicenter; follow-up } \\
\text { I, } 3,4.5 \text { years; Delphi score: } 7\end{array}$ & $\begin{array}{l}\text { DM ( } n=40 \text { surgical [one or } \\
\text { both legs] and } n=27 \text { nonsurgical } \\
\text { controls); painful DPN }\end{array}$ & $\begin{array}{l}\text { DNS peroneal (knee); deep } \\
\text { peroneal (foot); four tibial } \\
\text { tunnels (ankle), with neurolysis }\end{array}$ & $\begin{array}{l}\text { Pain: Likert } \\
\text { QOL }\end{array}$ \\
\hline $\begin{array}{l}\text { Tekin et al }(2015)^{44} \\
\text { Retrospective, unblinded; single-center; } \\
\text { follow-up } 3 \text { months; Delphi score: } 3\end{array}$ & DM ( $n=27) ;$ DPN; +Tinel & $\begin{array}{l}\text { DNS posterior and anterior } \\
\text { tarsal tunnel }\end{array}$ & $\begin{array}{l}\text { Doppler US: posterior tibial } \\
\text { artery }\end{array}$ \\
\hline $\begin{array}{l}\text { Trignano et al }(2016)^{45} \\
\text { Prospective, consecutive; unblinded; single- } \\
\text { center (Italy); follow-up I8 months; Delphi } \\
\text { score: } 2\end{array}$ & $\begin{array}{l}\text { DM }(n=20) ; \text { DPN and concurrent } \\
\text { bilateral tarsal tunnel syndrome; } \\
\text { no vascular disease; }+ \text { Tinel }\end{array}$ & $\begin{array}{l}\text { DNS tibial nerve (ankle) (four } \\
\text { legs had additional DNSs) }\end{array}$ & $\begin{array}{l}\text { Microcirculation: transcutaneous } \\
\text { oximetry dorsum foot }\end{array}$ \\
\hline $\begin{array}{l}\text { Wieman and Patel }(1995)^{38} \\
\text { Prospective, consecutive; unblinded; single- } \\
\text { center; follow-up: } \geq 2 \text { months (mean } 13 \\
\text { months); Delphi score: } 2\end{array}$ & $\begin{array}{l}\text { DM ( } n=28) \text {; painful DPN; +Tinel } \\
32 \text { of } 33 \text { ankles; no ischemia } \\
\text { (tibial and dorsalis pedis pulses) }\end{array}$ & $\begin{array}{l}\text { DNS tibial nerve (ankle); } \\
\text { internal neurolysis not } \\
\text { performed }\end{array}$ & $\begin{array}{l}\text { Pain: VAS } \\
\text { Sensation: T-P; 2PD } \\
\text { NCS: “standard studies" }\end{array}$ \\
\hline $\begin{array}{l}\text { Wood and Wood }(2003)^{39} \\
\text { Prospective, consecutive, unblinded; single- } \\
\text { center; follow-up } \geq 1 \text { month (I-6, mean 3); } \\
\text { Delphi score: } 2\end{array}$ & $\begin{array}{l}\text { DM }(n=33) ; \text { symptomatic DPN } \\
\text { (pain }[n=30] \text { and/or numbness); } \\
\text { nine had NCS confirmed DPN; } \\
+ \text { Tinel; ankle/brachial index } \geq 7\end{array}$ & $\begin{array}{l}\text { DNS of peroneal (knee); deep } \\
\text { peroneal (foot); four tibial } \\
\text { tunnels (ankle) }\end{array}$ & $\begin{array}{l}\text { Pain: VAS } \\
\text { Sensation: 2PD } \\
\text { Subjective: excellent, good, fair, } \\
\text { or failure }\end{array}$ \\
\hline $\begin{array}{l}\text { Yang et al }(2016)^{30} \\
\text { Prospective, consecutive, unblinded; single- } \\
\text { center; follow-up I, } 2 \text { years; Delphi score: } 2\end{array}$ & $\begin{array}{l}\text { TIDM }(n=4) \text { or T2DM }(n=7) \\
\text { DM; painful DPN for } \geq 2 \text { years; } \\
\text { +Tinel; } 2 \text { PD (great toe) }>8 \mathrm{~mm} \text {; } \\
\text { no limb ischemia }\end{array}$ & $\begin{array}{l}\text { DNS peroneal (knee); deep } \\
\text { peroneal (foot); four tibial } \\
\text { tunnels (ankle) }\end{array}$ & $\begin{array}{l}\text { Pain: VAS } \\
\text { Sensation: } 2 \text { PD } \\
\text { QOL }\end{array}$ \\
\hline $\begin{array}{l}\text { Zhang }(2013)^{40,87} \text { (overlapping data) } \\
\text { Prospective, consecutive, sensory technician } \\
\text { blinded; single-center; follow-up } 18 \text { months } \\
\text { (ulcer follow-up: } 2-5 \text { years); Delphi score: } 4\end{array}$ & $\begin{array}{l}\text { DM type } 2(n=560) ; \text { DM controls } \\
\text { without DPN }(n=40) ;+ \text { Tinel; } \\
2 \text { PD (great toe })>9 \mathrm{~mm}\end{array}$ & $\begin{array}{l}\text { DNS peroneal (knee); deep } \\
\text { peroneal (foot); four tibial } \\
\text { tunnels (ankle) with neurolysis }\end{array}$ & $\begin{array}{l}\text { Ulcer: new or recurrent } \\
\text { Sensation: 2PD, CPT, thermal } \\
\text { NCS: TMA, PMA, SPA, SSC } \\
\text { (CV) } \\
\text { US: CSA tibial and peroneal } \\
\text { nerves } \\
\text { TCS: symptoms and signs }\end{array}$ \\
\hline
\end{tabular}

Abbreviations: 2PD, two-point discrimination; A, amplitude; $\mathrm{ABI}$, ankle-brachial index; BPI, brief pain inventory; CPT, cold perception threshold; CSA, cross-sectional area; $\mathrm{CV}$, conduction velocity; DM, diabetes mellitus; DNS, decompression nerve surgery; DPN, distal symmetric diabetic peripheral neuropathy; NCS, nerve conduction study; PMA, peroneal motor, recording extensor digitorum brevis; PMAT, peroneal motor, recording anterior tibialis; PO, postoperative; QOL, quality of life; SSC, sural sensory, recording ankle; SPA, superficial peroneal, recording ankle; TBI, toe-brachial index; TCS, Toronto clinical scoring; TMA, tibial motor, recording abductor hallucis; T-P, touchpressure; TI, type I; T2, type 2; US, ultrasonography; VAS, visual analog scale.

from similar studies or values of $0.3,0.5$ (as if independent samples), and 0.7 were used. ${ }^{18-24}$ The resulting effect sizes were described in terms of the median value and range. The median effect sizes were combined across trials to calculate a weighted treatment effect, recognizing that some data were not distributed normally and the effect sizes may represent only approximations in some cases. The estimated effect sizes were intended to provide a subjective comparison across studies of DNS treatment and outcome, not a precise statistical measure.

\section{Results}

We identified 214 citations, of which 78 underwent full review (Figure 1). Data from a total of 24 articles were included in our analyses, describing 20 unique cohorts.

\section{Primary outcome (pain relief)}

Dellon et al enrolled 628 patients with symptomatic DPN and a positive tarsal tunnel Tinel sign in a prospective, multicenter study of DNS. ${ }^{25}$ DNS included release at the tarsal tunnel 
Table 2 Assessment of bias scored as high, unclear, or low risk of bias

\begin{tabular}{|c|c|c|c|c|c|c|c|}
\hline Author & $\begin{array}{l}\text { Random } \\
\text { sequence } \\
\text { generation }\end{array}$ & $\begin{array}{l}\text { Allocation } \\
\text { concealment }\end{array}$ & $\begin{array}{l}\text { Blinding } \\
\text { (participant) }\end{array}$ & $\begin{array}{l}\text { Blinding } \\
\text { (observer) }\end{array}$ & $\begin{array}{l}\text { Incomplete } \\
\text { outcome data }\end{array}$ & $\begin{array}{l}\text { Selective } \\
\text { reporting }\end{array}$ & Other bias \\
\hline Aszmann et $\mathrm{al}^{34,37}$ (duplicate) & High & High & High & Low & High & Unclear & Low \\
\hline Aszmann et $\mathrm{al}^{50}$ & High & High & High & High & High & Unclear & Low \\
\hline Dellon ${ }^{41}$ & High & High & High & High & High & Unclear & Low \\
\hline Dellon et $\mathrm{al}^{25}$ & High & High & High & High & High & High & Low \\
\hline Dellon et al $9^{84}$ & High & High & High & High & High & High & Low \\
\hline Karazog et $\mathrm{al}^{26}$ & High & High & High & High & High & Unclear & Low \\
\hline Knobloch et $\mathrm{al}^{27}$ & High & High & High & High & High & Unclear & Low \\
\hline Lee and Dellon ${ }^{85}$ & High & High & High & High & High & Unclear & Low \\
\hline Liao et $\mathrm{a}^{28}$ & High & High & High & High & High & High & Low \\
\hline Macaré van Maurik et al ${ }^{33}$ & Low & High & High & Low & Low & Low & Low \\
\hline Macaré van Maurik et al ${ }^{42}$ & Low & High & High & Low & Low & Low & Low \\
\hline Macaré van Maurik et al ${ }^{3 !}$ & Low & High & Low & High & Low & Low & Low \\
\hline Macaré van Maurik et al ${ }^{66}$ & Low & High & Low & High & Low & Low & Low \\
\hline Nickerson ${ }^{46}$ & High & High & High & High & Low & Low & Low \\
\hline Nickerson $^{86}$ & High & High & High & High & Low & Low & Low \\
\hline Nickerson and Rader ${ }^{49}$ & High & High & High & High & Low & Low & Low \\
\hline Rader $^{29}$ & High & High & High & Low & High & Lo & Low \\
\hline Rozen et a $\left.\right|^{32}$ & Low & Unclear & Low & Low & Unclear & Unclear & Low \\
\hline Tekin et $\mathrm{al}^{44}$ & High & High & High & High & Low & Low & Low \\
\hline Trignano et $\mathrm{al}^{45}$ & High & High & High & High & High & Unclear & Low \\
\hline Wieman and Patel ${ }^{38}$ & High & High & High & High & High & Unclear & Low \\
\hline Wood and Wood ${ }^{39}$ & High & High & High & High & High & Unclear & Low \\
\hline Yang et $\mathrm{al}^{30}$ & High & High & High & High & High & Unclear & Low \\
\hline Zhang $^{40,87}$ (duplicate) & High & High & High & Low & High & Unclear & Low \\
\hline
\end{tabular}

and neurolysis of the medial and lateral plantar and calcaneal tunnels. VAS pain scores $(0-10)$ were recorded before and at $6,12,24$, and 42 months post-DNS. The primary efficacy analyses included 465 participants who had a VAS pain score $>5$, of whom 152 had bilateral symptoms, resulting in the report of 617 operated limbs. The mean VAS score decreased from 8.5 to 2.0 at 6 months post-DNS and remained between 1 and 2 for 3.5 years. The authors concluded that a positive Tinel sign predicted a successful pain relief post-DNS; no comparison group having a negative Tinel sign was included.

Seven additional observational studies reported VAS pain scores pre-DNS and at intervals post-DNS ranging from days to several years. DNS typically included the common peroneal, deep peroneal, and the four medial ankle tunnels (tarsal, medial and lateral plantar, and calcaneal). Pre- and post-DNS VAS pain scores are summarized in Table 3. In 2008, Karagoz et al reported VAS pain scores among 24 participants with painful DPN (16 diabetes mellitus type [DMT]1 and 8 DMT2) immediately (day 1) and at 6 months after DNS. ${ }^{26}$ Twelve cases had nonhealing neuropathic foot ulcers, three had toe amputations, and one had a contralateral leg amputation, factors indicating a substantial DPN. Pain reduction was apparent 1 day post-DNS, although the use of postoperative medications is unclear. Improvement persisted at the 6-month evaluation, representing a mean pain reduction of 4.8 \pm 3.0 . Knobloch et al reported similar results, but with slightly less improvement $12 \pm 6$ months post-DNS among 12 participants with painful DPN and a positive tarsal Tinel sign. ${ }^{27}$ Liao et al described 306 DNS participants with painful DPN, separated on the basis of diffuse $(n=161)$ or focal pain $(\mathrm{n}=145) .{ }^{28}$ Pre-DNS scores were similar for both groups. One year post-DNS, the VAS scores were substantially lower for both groups ( $3.3 \pm 2.7$ and $2.3 \pm 1.7$, respectively); pain relief persisted and increased 2 years post-DNS $(2.5 \pm 2.8$ and $1.0 \pm 1.6$, respectively). (SDs were estimated from Figure 1 of their article.) In a prospective study, Rader described the results of DNS among 38 participants with painful DPN (6 DMT1 and 32 DMT2). ${ }^{29}$ Ten of the 38 had bilateral surgery. Pain relief was substantial and rapid, being apparent at 1 week post-DNS and persisting and increasing at the final visit (3-18 months). Wood and Wood ${ }^{39}$ described the short-term results of unilateral DNS and neurolysis among 30 participants with painful DPN that were comparable to the other reports. In 2016, Yang et al reported the results of DNS at daytime, nighttime, and during peak pain (VAS scores) among eleven participants with intractable DPN pain at 2 weeks and 3, 6, 12, 


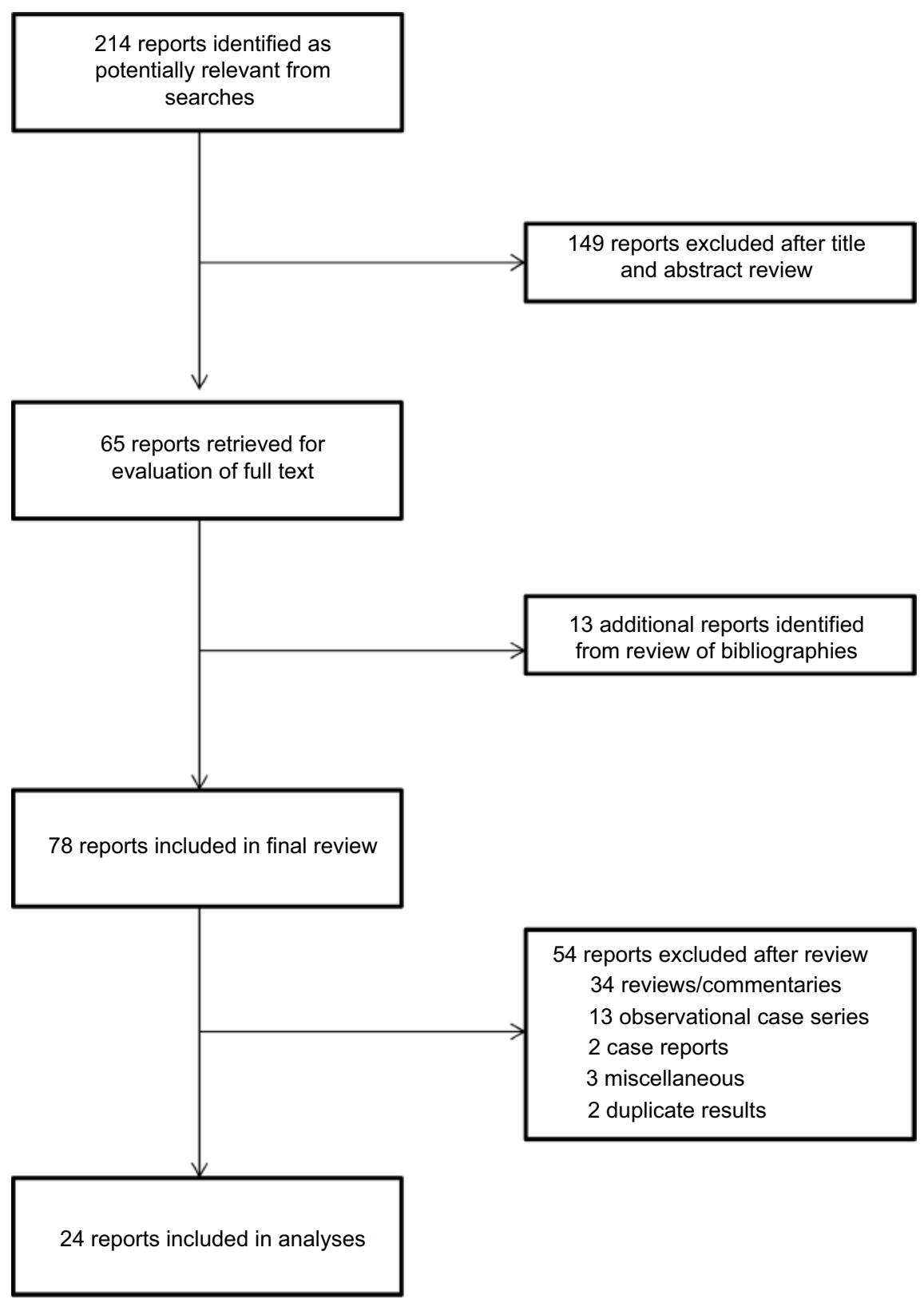

Figure I Flow diagram of literature search results.

and 24 months post-DNS. ${ }^{30}$ All three pain measures showed substantial improvement. For example, daytime pain fell from $7.9 \pm 0.6$ to $4.5 \pm 1.5,2.1 \pm 1.9$, and $1.8 \pm 2.1$ at $0.5,12$, and 24 months post-DNS, respectively. The daytime, nighttime, and peak pain scores showed comparable improvement for each interval and the results were combined.

Macaré van Maurik et al reported the results of DNS among 40 participants with painful DPN. ${ }^{31}$ This study differed from the preceding observational studies, in that DNS was randomized to one leg while the other served as a control. The baseline pain score for these 38 participants also differed from the remaining studies, being the lowest included in our review ( $6.1 \pm 1.9$ bilaterally). Post-DNS, the pain scores for the surgical leg were significantly improved at 3 months (2.8, SD neither provided nor available on request), an effect that was essentially maintained at 6 and 12 months (3.1 \pm 1.2 and 3.5 \pm 3.0 , respectively, representing a pre- to post-DNS difference of $2.6 \pm 0.6$ at 12 months). The pain scores for the surgical leg were significantly improved relative to the nonsurgical control leg scores, although, perhaps unexpectedly, the mean scores for the nonsurgical leg were improved post-DNS, although to a lesser extent. The control leg scores were significantly higher than the surgical leg scores at all intervals, but were significantly improved 


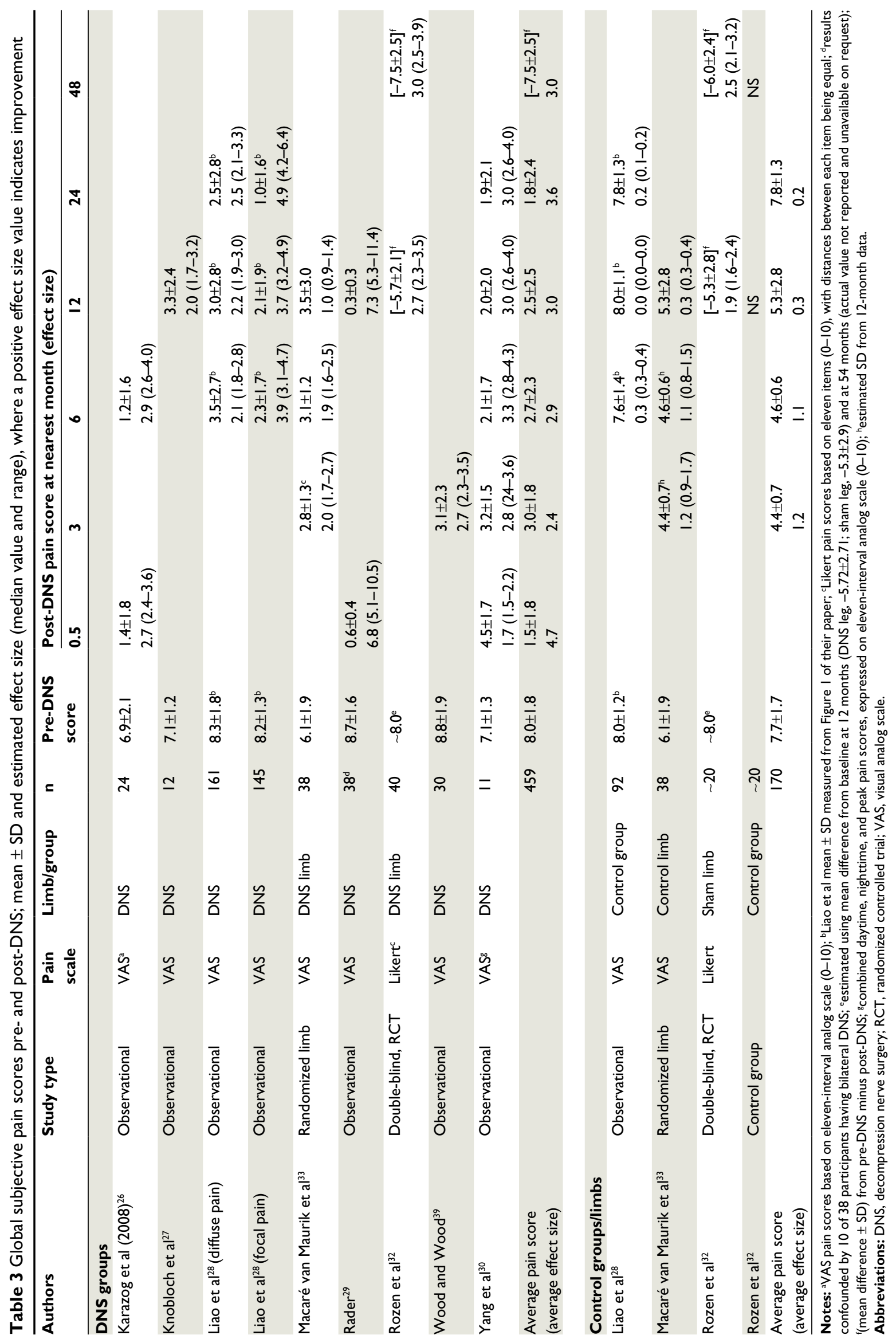


relative to pre-DNS score at 3 and 6 months, but not at 12 months (pre- to post-DNS difference of $0.8 \pm 0.4$ ). This initial improvement, albeit modest, in the scores for the nonsurgical leg post-DNS on the contralateral leg contrasts with the VAS scores reported by Liao et al for control subjects who refused surgery. ${ }^{28}$ Namely, those controls had a mean VAS of 8.0 at the first visit, which remained unchanged during the 2-year follow-up.

The average effect size estimates resulting from the unblinded observational studies (also shown in Table 3) showed comparable results. The overall weighted-effect size following DNS was substantial. The largest effect size exceeded four and was observed shortly post-DNS, although these results were driven by a single study. ${ }^{29}$ Nonetheless, highly favorable effect size results of 2.4-3.6 were sustained over 6-48 months. Control data obtained for participants who declined surgery showed essentially no change over a 6-24month interval, with a maximum effect size of $<0.3$ relative to baseline scores. ${ }^{28}$ In contrast, the modest but unexpected pain reduction in the nonsurgical leg noted by Macaré van Maurik et al corresponded to an effect size of about 1.2 at 3 and 6 months after contralateral surgery, falling to 0.3 at 12 months, substantially less than the effect size of 1.0 for the DNS leg. ${ }^{31}$

Rozen et al reported the results of the only prospective, double-blind, randomized controlled trial (RCT) of DNS to investigate the long-term effects on pain in painful DPN (in abstract form, ${ }^{32}$ full publication pending, S Rozen, University of Texas Southwestern Medical Center, personal communication, 2018). Participants were randomized into surgical and nonsurgical groups (2:1 ratio). Within the surgical group, participants were randomized to DNS/neurolysis (DNS surgery) on one side or a sham surgery on the other side, using identical incisions and dressings. Participants and evaluators were blinded to the DNS side. Baseline pain and HbA1c levels were similar in the DNS and sham surgery groups. Pain levels were scored using a Likert (0-10) scale, as opposed to the VAS scores reported for the studies described above. Of 138 enrolled, 92 were randomized to DNS and 48 to the control group; $40 \mathrm{DNS}$ and 27 control participants participated in the 1-year evaluation and 36 in the 4-year evaluation. After 1 year, the surgical participants experienced a mean pain reduction of $5.7 \pm 2.1$ in the surgical leg and $5.3 \pm 2.8$ in the sham leg; both were significantly different from baseline and from nonsurgical controls, but not from each other. In contrast, the control group showed no significant pain reduction from baseline. At the long-term follow-up (mean 54.5 months), 36 surgical participants experienced a mean pain reduction of 7.5 \pm 2.5 in the DNS leg and $6.0 \pm 2.4$ in the sham leg, both still significantly different not only from baseline, but also from each other.

The pain relief associated with ipsilateral DNS was comparable to that reported from the observational studies at 12 months (eg, effect sizes of 2.7 vs 2.5 , respectively). The pain relief reported for the sham surgery leg at 12 months was slightly lower than that reported for the DNS leg, but far greater than the values reported for nonsurgical controls by Liao et $\mathrm{al}^{28}$ or for the leg contralateral to DNS surgery reported by Macaré van Maurik et $\mathrm{al}^{33}$ in their unblinded study. The general magnitude of the mean pain reduction at 1 year in the sham leg in this RCT was substantially greater than the mean pain reduction in the nonsurgical leg in the unblinded trial of Macaré van Maurik et al (eg, -5.3 Likert pain score [effect size of 1.9] vs -0.8 VAS pain score [effect size of 0.3 ], respectively). In other words, the effect size at 12 months for the sham surgery leg of 1.9 was intermediate between the mean effect size for the DNS leg calculated for the observational studies (3.0) and the control leg effect size reported by Macaré van Maurik et al (effects sizes of 3.0 vs 1.9 vs 0.3 , respectively). At 54 months postsurgery, the DNS and sham surgery legs showed pain relief effect sizes of 3.0 and 2.5, respectively (control leg data not available, but not significantly different from baseline scores).

\section{Secondary outcomes}

\section{Sensation}

\section{Two-point discrimination}

2PD was reported in nine studies, of which three included a comparison to a nonsurgical $\operatorname{limb}^{33,34}$ or a control group..$^{28}$ Static 2PD (one or two points applied), moving 2PD (one or two points moved along the skin), or both were at times reported..$^{35}$ The results for each were generally comparable, differing only in magnitude (static 2PD larger than moving 2PD), and the results are reported for static 2PD.

Three studies provided subjective descriptions of $2 \mathrm{PD}$ results. ${ }^{25,26,36}$ Dellon et al described progressive improvement in sensation among 628 participants undergoing DNS (152 bilaterally), with some $2 \mathrm{PD}$ being recovered at 1 year and the mean $2 \mathrm{PD}$ returning to the normal range at 2 years post-DNS. ${ }^{25}$ Karagoz et al reported 2PD post-DNS (presumably bilaterally, but not specified) for 24 participants; 18 had improved 2PD immediately postop (day 1) and 21 had improved 2PD 6 months later. ${ }^{26}$ They reported that 2PD for four leg sites (great toe, web space, heel, and calf) was improved on postop day $1(73 \%)$ and at 6 months $(89 \%)$. Valdivia et al reported that $93 \%$ of 60 participants with symptomatic DPN experience decreased (improved) 2PD 12 
or more months post-DNS (evaluation confounded by inclusion of 40 patients with idiopathic neuropathy). ${ }^{36}$

Aszmann et al described 20 consecutive cases of DNS for DPN, including 12 cases that had posterior tibial DNS. ${ }^{37}$ The non-DNS leg served as a control, although four participants had bilateral DNS before completion of the study to extend improvements to the opposite leg, leaving eight cases for comparison. After at least 12 months post-DNS, static 2PD recorded at the great toe pulp improved $\geq 2 \mathrm{~mm}$ in seven of eight DNS limbs and four of eight control legs, a nonsignificant difference (assuming ordered pairs from the published data in Figure $1, P=0.48$, McNemar's test). The mean 2PD values (Figure 1 in the article) pre- and post-DNS were $16.0 \pm 4.4$ and $12.3 \pm 4.6 \mathrm{~mm}$ for the surgical leg $(P<0.01)$ and $14.3 \pm 4.8$ and $14.1 \pm 5.1 \mathrm{~mm}$ for the control leg $(P=0.4)$. The authors concluded that the sensation was improved, although the pre- and post-DNS change in 2PD for the two legs was not significant ( $P=0.12$, paired $t$-test). The report of Liao et al involving 306 patients with painful DSN (145 had focal pain and 161 had diffuse pain) who underwent bilateral DNS and a comparison group of 92 eligible cases that had refused surgery included measurement of 2PD pre-DNS and 2 years post-DNS. ${ }^{28}$ Comparable results were found at the great and fifth toes (great toe results are shown). Participants with diffuse pain showed significantly worse $2 \mathrm{PD}$ than those with focal pain at baseline (18.7 $\pm 1.7 \mathrm{vs} 17.4 \pm 1.9 \mathrm{~mm})$ and 2 years post-DNS (7.3 \pm 1.5 vs $6.4 \pm 1.5 \mathrm{~mm})$. Both groups showed slightly, but significantly worse $2 \mathrm{PD}$ relative to the control group at baseline (combined pre-DNS result of $17.9 \pm 2.0 \mathrm{vs}$ $16.3 \pm 1.8 \mathrm{~mm}$ ), whereas post-DNS, $2 \mathrm{PD}$ was significantly improved and markedly better than the control group 2PD (6.9 \pm 1.5 vs $17.8 \pm 1.7 \mathrm{~mm})$, which showed little change from baseline. Rader reported mean 2PD values (medial plantar and deep peroneal sites) for 39 participants (49 limbs) preDNS and 3 and 6 months post-DNS. ${ }^{29}$ Only the mean values were reported. The combined mean for the two nerve sites were $16.7 \mathrm{~mm}$ pre-DNS, $12.5 \mathrm{~mm} 3$ months post-DNS, and $11.1 \mathrm{~mm} 6$ months post-DNS. Wieman and Patel reported 2PD results $2-26$ months post-DNS (some bilateral). ${ }^{38}$ Baseline mean 2PD of $13.7 \pm 2.9 \mathrm{~mm}$ (better than most results reported above) improved to $11.7 \pm 2.5 \mathrm{~mm}$ at $1-6$ months post-DNS (worse than most results reported above; paired data unavailable). Wood and Wood reported 2PD (great toe) recorded from 33 participants with painful DPN. ${ }^{39}$ Baseline 2PD of $18.0 \pm 2.7 \mathrm{~mm}$ improved at $1-3$ months post-DNS to $12.8 \pm 4.9 \mathrm{~mm}(P<0.0001$, paired $t$-test $)$. Zhang et al reported $2 \mathrm{PD}$ results (great toe) for $560 \mathrm{DPN}$ participants. ${ }^{40}$ The $2 \mathrm{PD}$ values improved significantly from $>9 \mathrm{~mm}$ at baseline to
$6.7 \pm 1.6 \mathrm{~mm}$ post-DNS. The post-DNS results of Wood and Wood and Zhang et al were comparable to those reported by Liao et al. ${ }^{29}$

In 2014, Macaré van Maurik, et al reported the 2PD results of pre- and 6 months post-unilateral DNS obtained from 42 patients with painful DPN. ${ }^{33}$ They recorded $2 \mathrm{PD}$ from nine plantar sites; "no discrimination" was recorded if the participant was unable to distinguish two points at $25 \mathrm{~mm}$. At baseline, the 2PD evaluations for the surgical and control legs were not significantly different. After 12 months, there was no significant improvement, and participants capable of performing 2PD testing at baseline showed significantly worsened 2PD for the surgical and control legs (actual 2PD measurements were not reported).

Study outcomes from most trials cannot be combined because of differing protocols and data reporting methods. The pooled results from five studies reporting 2PD values from the great toe showed pre- and post-DNS values of $12.8 \pm 4.6$ and $7.0 \pm 2.0 \mathrm{~mm}$, respectively $(\mathrm{n}=907$, final evaluation), as shown in Table 4. ${ }^{28,34,38-40}$ Ignoring that the pre- and post-DNS samples are not independent, this difference is highly statistically significant (mean difference of $5.8 \mathrm{~mm}$ [95\% CI 5.5-6.1], $P<0.0001$ ). The average effect size postDNS for the five studies is 3.3. However, the results are not uniform. There is substantial variability in pre-DNS scores, with Zhang et al showing far better performance than the remaining four studies and the post-DNS effect sizes ranged from 0.8 to 7.1 across studies. The most favorable effect sizes were reported by Liao et al at 24 months post-DNS (average effect size of 6.8), but no other study showed an effect size exceeding 1.5 through 18 months DNS.

\section{Touch-pressure}

Six papers reported touch-pressure sensation pre- and postDNS. ${ }^{25,26,29,33,36,38}$ Dellon et al reported that touch-pressure sensation among 628 participants undergoing DNS (152 bilaterally) was normal (sic), but remained abnormal 2 years after DNS. ${ }^{25}$ Rader reported mean touch-pressure thresholds pre-DNS, 3 months post-DNS, and 6 months post-DNS of 50.6, 25.3 , and $15.8 \mathrm{~g} / \mathrm{mm}^{2}$, respectively, recorded for 39 participants (and 49 limbs), ${ }^{29}$ but no statistical evaluation of the improving mean values. Wieman and Patel reported a "pattern of overall improvement in tactile sensation" $1-6$ months post-DNS for 19 of 26 participants with DPN. ${ }^{38}$ Valdivia et al reported that $100 \%$ of 60 participants had improved touch-pressure sensation 12 or more months post-DNS (data not provided). ${ }^{36}$

Macaré van Maurik et al recorded touch-pressure sensation among 42 participants as the ability to feel a 5.07 (10 g) 
Table 4 2PD pre- and post-DNS; mean \pm SD and effect size (median value and range), where positive effect size value indicates improvement

\begin{tabular}{|c|c|c|c|c|c|c|c|c|}
\hline \multirow[t]{2}{*}{ Authors } & \multirow[t]{2}{*}{ Study type } & \multirow[t]{2}{*}{ Limb/group } & \multirow[t]{2}{*}{$\mathbf{n}$} & \multirow{2}{*}{$\begin{array}{l}\text { Pre-DNS } \\
(\mathrm{mm})\end{array}$} & \multicolumn{4}{|c|}{ Post-DNS (mm) at the nearest month (effect size) } \\
\hline & & & & & 3 & $6-12$ & 18 & 24 \\
\hline \multicolumn{9}{|l|}{ DNS groups } \\
\hline Aszmann et $\mathrm{al}^{34}$ & Observational & DNS & 8 & $16.0 \pm 4.4$ & & $\begin{array}{l}12.3 \pm 4.6 \\
0.8(0.7-1.1)\end{array}$ & & \\
\hline Liao et $\mathrm{a}^{28}$ (diffuse pain) & Observational & DNS & 161 & $18.7 \pm 1.7$ & & & & $\begin{array}{l}7.3 \pm 1.5 \\
7.1(6.0-9.2)\end{array}$ \\
\hline Liao et $\mathrm{al}^{28}$ (focal pain) & Observational & DNS & 145 & $17.4 \pm 1.9$ & & & & $\begin{array}{l}6.4 \pm 1.5 \\
6.4(5.5-8.4)\end{array}$ \\
\hline $\operatorname{Rader}^{29}$ & Observational & DNS & 39 & 16.7 & 12.5 & 11.2 & & \\
\hline Wood and Wood ${ }^{39}$ & Observational & DNS & 33 & $18.0 \pm 2.7$ & $\begin{array}{l}12.8 \pm 4.9 \\
1.3(1.2-1.8)\end{array}$ & & & \\
\hline Zhang et $\mathrm{al}^{40}$ & Observational & DNS & 560 & $9.5 \pm 2.0$ & & & $\begin{array}{l}6.7 \pm 1.6 \\
1.5(1.3-2.0)\end{array}$ & \\
\hline Average 2PD & & DNS & & $12.8 \pm 4.6$ & $12.8 \pm 4.9$ & $12.3 \pm 4.6$ & $6.7 \pm 1.6$ & $6.9 \pm 1.6$ \\
\hline Average effect size & & & & & 1.3 & 0.8 & 1.5 & 6.8 \\
\hline \multicolumn{9}{|l|}{ Control groups/limbs } \\
\hline Aszmann et $\mathrm{al}^{34}$ & Observational & Control limb & 8 & $14.3 \pm 4.8$ & & $\begin{array}{l}|4.1 \pm 5 .| \\
0.0(0.02-0.04)\end{array}$ & & \\
\hline Liao et $\mathrm{al}^{28}$ & Observational & Control group & 92 & $16.3 \pm 1.8$ & & & & $\begin{array}{l}17.8 \pm 1.7 \\
-0.8(0.7-1.1)\end{array}$ \\
\hline
\end{tabular}

Abbreviations: 2PD, two-point discrimination; DNS, decompression nerve surgery.

Semmes Weinstein monofilament scored for nine plantar sites. ${ }^{33}$ At baseline, the mean scores for the designated DNS and control legs did not differ significantly (3.9 vs 3.6 sites). Three months post-DNS, the DNS leg mean score (5.4) had improved significantly relative to baseline and to the control leg score (4.0). At 6 and 12 months post-DNS, the improvement was not sustained and the scores had deteriorated to 4.8 and 4.6, respectively, scores no longer significantly different from baseline or the control leg scores (4.1 and 4.1 , respectively). Karagoz et al reported mean pressure thresholds among 24 participants with DPN pre- and postDNS (presumably bilaterally) measured at four sites (great toe, web space, heel, and calf). ${ }^{26}$ Mean pressure thresholds were improved relative to baseline immediately post-DNS (day 1), with further improvement observed at 6 months. The thresholds $\left(\mathrm{g} / \mathrm{mm}^{2}\right)$ were improved to a similar extent for each site at each of the three evaluations, with average scores of $91.5 \pm 16.3$ preoperative, $51.3 \pm 25.2$ day $1,38.8 \pm 21.2$ at 6 months, representing a substantial average effect size of about $1.8(1.6-2.5)$ at day 1 and $2.8(2.4-3.6)$ at 6 months.

\section{Quantitative sensory testing}

Zhang et al reported improved quantitative sensory thresholds among 560 DPN participants who underwent DNS, including cold perception $\left(21.1^{\circ} \mathrm{C} \pm 0.6^{\circ} \mathrm{C}\right.$ to $\left.26.3^{\circ} \mathrm{C} \pm 2.3^{\circ} \mathrm{C}, P<0.05\right)$, warm perception $\left(46.3^{\circ} \mathrm{C} \pm 2.3^{\circ} \mathrm{C}\right.$ to $\left.39.8^{\circ} \mathrm{C} \pm 2.3^{\circ} \mathrm{C}, P<0.001\right)$, and vibration perception $(9.2 \pm 2.2-6.2 \pm 3.6 \mu \mathrm{m}) .{ }^{40}$ The average standardized effect size was 2.3 , results similar to those reported for touch-pressure sensation.

\section{Nerve conduction studies}

In 1992, Dellon described the NCS results of 40 cases of symptomatic DPN evaluated pre- and post-DNS (6-83 months). ${ }^{41}$ The cases included a combination of upper and lower extremity studies and the results were reported generally, indicating that $100 \%$ of the localized compression cases, $55 \%$ of the diffuse neuropathy cases, and $80 \%$ of the peripheral neuropathy plus compression cases showed electrodiagnostic improvement (not further defined). Wieman and Patel reported 26 DNS participants who had "electrodiagnostic studies carried out in the standard fashion, but with emphasis on any likely nerve compression components". ${ }^{38}$ Pre-DNS, all participants showed evidence of axonal loss and nerve CV slowing, but no consistent relationship between localized symptoms and the distribution of nerve abnormalities. They concluded that no significant information was obtained from the electrodiagnostic testing, as pre- and post-DNS NCS test results did not "vary markedly" in any patient.

Pre- and post-DNS NCS results are shown in Table 5. Only one study reported response amplitudes and distal latencies (tibial and peroneal motor) pre- and post-DNS. ${ }^{42}$ Limbs were warmed in $37^{\circ} \mathrm{C}$ water for 30 minutes and kept warm 


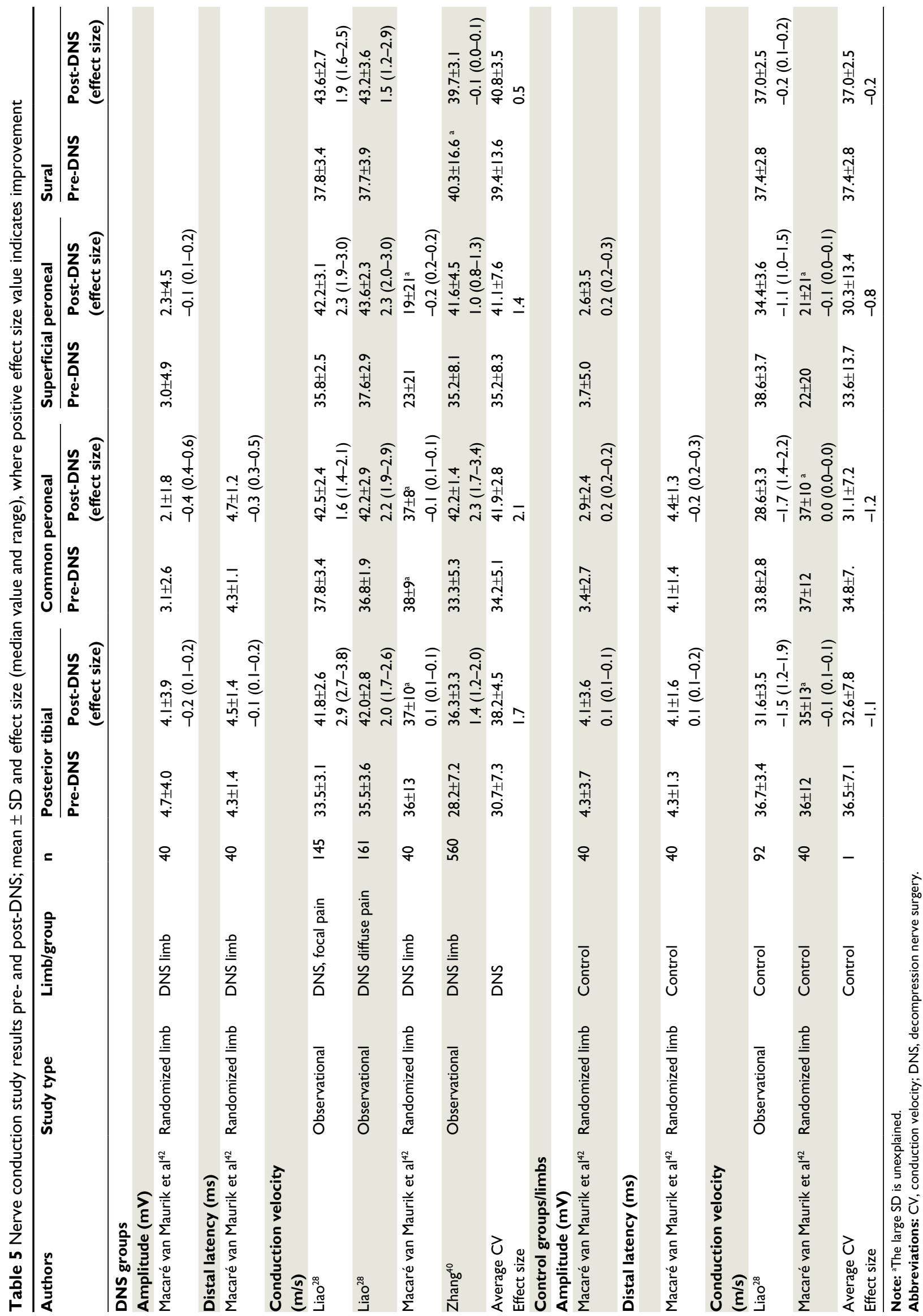


under an infrared heater set at $37^{\circ} \mathrm{C}$ to minimize the effect of temperature on NCS results. Twelve months post-DNS, there was a slightly but significantly reduced peroneal motor amplitude (3.1 \pm 2.6 vs $2.1 \pm 1.8 \mathrm{mV}, P \leq 0.001)$ and a prolonged peroneal motor distal latency $(4.3 \pm 1.1$ vs $4.7 \pm 1.2 \mathrm{~ms}, P \leq 0.01)$ relative to baseline. Both changes represent deterioration (effect size of -0.4 for the peroneal amplitude). There was no significant change in the tibial motor and superficial peroneal sensory amplitudes or in the tibial distal latency. Nerve CVs demonstrated no significant change, but showed a very large SD that was not explained. There were no clinically important NCS differences between the surgical and control legs. The authors concluded that DNS for painful DPN had no beneficial effect on NCS results 12 months after surgery.

Two other studies reported CV results. ${ }^{28,40}$ Liao et al found that CVs were improved post-DNS in the surgical group compared to the 92 controls group who declined surgery. ${ }^{28}$ Improvement was similar among participants with focal or diffuse pain, with an average effect size for all four nerves of about 2.1. In contrast, their control group showed substantial deterioration during the same interval, with an average effect size of -1.1 . They also evaluated the sural sensory nerve, a nerve not decompressed. The sural CV showed significant improvement post-DNS in both pain groups, although the effect size was lower than that of the three decompressed nerves, albeit still large (average of 1.67 for both groups). In a similar study design, Zhang et al reported the DNS significantly improved tibial, common peroneal, and superficial peroneal $\mathrm{CVs}$, but not sural $\mathrm{CV}^{40}$ Their sural $\mathrm{CV}$ data showed a very large $\mathrm{SD}$, something not explained. Zhang et al reported $\mathrm{CVs}$ for the posterior tibia, common peroneal, superficial peroneal, and sural nerves pre-DNS and 18 months post-DNS among 560 participants with DPN and 40 diabetic controls without neuropathy. ${ }^{40} \mathrm{CVs}$ improved post-DNS in all but the sural nerve, the only nerve not decompressed (sural nerve results that differed from those reported by Liao et al above).

Overall, the combined effect size involving CVs averaged about 1.4. The effect size for decompressed nerves ranged from 1.4 to 2.1 and averaged 1.7, a substantial improvement. In contrast, the effect size for the ipsilateral sural nerve averaged 0.5 , much smaller albeit still improved. In contrast, the CVs recorded from the control groups or control limbs all showed deterioration, with an average effect size of -1.0 for the tibial and two peroneal nerves and -0.2 for the sural nerve.

\section{Ultrasound}

Liao et al used high-resolution US to determine the crosssectional area (CSA) of the tibial nerve (calculated at the distal tip of the lateral malleolus) and the common peroneal nerve (calculated $1.5 \mathrm{~cm}$ below the distal tip of the fibular head). ${ }^{28}$ At baseline, the tibial and peroneal nerve caliber did not differ significantly among the pre-DNS participants (focal and diffuse pain group results were combined) and symptomatic controls who declined DNS. All groups showed fusiform nerve swellings. The tibial nerve CSA of $25.2 \pm 3.8 \mathrm{~mm}$ recorded just above the lateral malleolus was significantly larger than the values reported by Riazi et al for measurements $1 \mathrm{~cm}$ above the lateral malleolus for diabetic subjects with DPN $\left(23.0 \pm 8.7 \mathrm{~mm}^{2}, P<0.01\right)$ and dramatically larger than the areas reported for diabetic subjects without neuropathy $\left(18 \pm 6.5 \mathrm{~mm}^{2}, P<0.001\right) .{ }^{43}$ Two years post-DNS, the CSAs were significantly decreased from baseline for the tibial (from $25.2 \pm 3.8$ to $18.4 \pm 3.8 \mathrm{~mm}^{2}$ ) and common peroneal (from $21.0 \pm 3.8$ to $15.3 \pm 3.2 \mathrm{~mm}^{2}$ ) nerves. During the same interval, the controls remained relatively unchanged: tibial nerve $\left(24.4 \pm 4.2\right.$ vs $\left.25.1 \pm 3.6 \mathrm{~mm}^{2}\right)$ and peroneal nerve $\left(21.6 \pm 3.7\right.$ vs $\left.21.9 \pm 3.2 \mathrm{~mm}^{2}\right)$. Liao et al described slightly more favorable morphological restoration (greater reduction of CSA) of the tibial and peroneal nerves post-DNS among participants who reported focal pain relative to those who reported diffuse pain. Zhang et al reported subjective findings from high-resolution US of the tibial and peroneal nerves, describing fusiform nerve swelling with increased CSA pre-DNS that "improved significantly after decompression" (data not reported).

The only other study that used US to determine nerve CSA found results somewhat different from those described above. For example, in a study of 42 participants undergoing DNS (32 of whom had US measurements of the tibial nerve at the tarsal tunnel), Macaré van Maurik et al also found that the tibial nerve CSA and the thickness of the flexor retinaculum were significantly larger among diabetic participants with painful DPN relative to their healthy controls. ${ }^{31}$ However, repeat (unblinded) evaluations performed an average of 28 weeks post-DNS (tarsal tunnel release) showed "a decrease" in the tibial CSA, but no significant difference in the CSA from baseline or between the operated leg and the control leg.

\section{Microcirculation}

Tekin et al used US to evaluate the hemodynamic and morphological parameters in posterior tibial and dorsalis pedis arteries. ${ }^{44}$ They studied 27 participants with DPN, pre-DNS and 3 months post-unilateral DNS. All measures showed statistically significant improvement post-DNS (described for the posterior tibial artery, as the dorsalis pedis results were comparable). The tibial mean flow lumen diameter 
was unchanged $(2.5 \pm 0.6$ vs $2.5 \pm 0.6 \mathrm{~mm})$, but the pulsatile index $(5.8 \pm 2.8$ vs $7.2 \pm 3.1)$, resistance index $(0.94 \pm 0.04$ vs $0.89 \pm 0.05)$, and flow volume $(19.4 \pm 5.8$ vs $22.7 \pm 7.1 \mathrm{~mL} /$ min) were all significantly improved post-DNS (decreased resistance, increased flow volume). The control limb was not evaluated. Trignano et al reported transcutaneous oximetry results (dorsum of foot, $\mathrm{PtCO}_{2}$ ) pre-DNS and at 1 and 18 months post-DNS (tarsal tunnel release, 36 bilateral) among 20 participants with DPN and superimposed nerve compression. ${ }^{45}$ The mean $\mathrm{PtCO}_{2}$ was $29.1 \mathrm{mmHg}$ pre-DNS (average of both sides), with all 40 values lower than the critical value of $40 \mathrm{mmHg}$. Post-DNS, $\mathrm{PtCO}_{2}$ significantly increased, averaging $45.8 \pm 6.4 \mathrm{mmHg}$ at 1 month (with four critical values) and $46.8 \pm 6.7 \mathrm{mmHg}$ at 18 months (with two critical values).

\section{Neuropathic DFU formation}

\section{Recurrent ulcer formation}

Nickerson reported the results of a retrospective review of 65 diabetic patients with a DPN and a previous or current neuropathic DFU (involving 75 feet) who underwent DNS. ${ }^{46}$ During the mean of 2.5 years post-DNS, eight recurrent DFUs developed in the 75 DNS legs. This $4.3 \%$ annual recurrence risk compared with standard care (daily foot inspection) of nearly $25 \%$ and "enhance care" (daily foot inspection and infrared measurements of foot temperature) rates of $8.5 \% .{ }^{47}$ Nickerson and Rader reported the extended follow-up of this cohort, an additional 3 years, during which a total of nine neuropathic DFUs recurred (annual recurrence risk of $2.6 \%$ per foot). ${ }^{48}$ The same authors reported the prospective frequency of a recurrent or new DFU among 42 diabetic patients who underwent unilateral DNS and neurolysis for pain control in the leg having at least one previous healed neuropathic DFU and palpable pulses. ${ }^{49}$ The contralateral (non-operated) leg served as a control. During 3 years of follow-up, operated legs developed two recurrent DFUs (4.8\% or $1.6 \%$ annual recurrence risks), whereas nine contralateral control legs developed a first DFU $(21.4 \%$ or $7.1 \%$ annual recurrence risk; $P=0.07, \mathrm{McNemar}$ 's test for paired proportions; no participant had bilateral ulcers). Zhang et al reported 18-months of follow-up after bilateral DNS (no control limb or group) for DPN, with most participants having asymmetrical limb pain. ${ }^{40}$ Among 208 participants who had a neuropathic DFU prior to DNS, all ulcers healed and no participant developed a recurrent ulcer or a contralateral first ulcer (vs 22 expected first DFUs, using the 7\% annual recurrence risk of contralateral first DFUs reported by Nickerson and Rader $^{49}$ for non-operated control legs; $P=0.001$, Fisher's exact test). Trignano et al reported the results of DNS (tar- sal tunnel release, 36 bilateral) among 20 participants with DPN and superimposed nerve compression, as defined by a positive Tinel sign and electroneurography but not further described). ${ }^{45}$ Eight participants presented with a DFU; postDNS, all ulcers healed and there were no recurrences in the eight limbs over the next 18 months.

\section{New ulcer formation}

Azsmann et al retrospectively evaluated the development of initial neuropathic DFUs (and amputations) involving the operated and the contralateral, non-operated, limbs. ${ }^{50}$ They identified 50 patients with painful DPN followed for at least 2 years after unilateral DNS (mean of 4.5 years, range, 2-7 years). ${ }^{50}$ Reasons for not having bilateral DNS included deterioration in overall health, travel considerations, and incomplete relief of pain or recovery of sensibility following the initial operation. No neuropathic DFUs/amputations occurred in the DNS limbs, whereas 15 different patients experienced 12 neuropathic DFUs and three amputations involving the contralateral non-operated limbs (annual first DFU risk of 6.7\%). The difference in DFU/amputation between the DNS and non-operated legs was significant $(P<0.001$, McNemar's test for paired proportions). This population differed from the cohort reported by Nickerson and Rader in that none of the patients had a previous DFU. Zhang et al reported that during 2-5 years after bilateral DNS was performed for DPN (with most patients having asymmetrical limb pain), 3 of 352 participants developed a new neuropathic DFU. ${ }^{40}$ The description that the patients had asymmetric leg pain is notable, as typical DPN is generally symmetrical. There was no control limb or group. Trignano et al reported the results of DNS (tarsal tunnel release, 36 bilateral) among 20 participants with DPN and superimposed nerve compression. ${ }^{45}$ Eight participants presented with a DFU, all of which healed. No new ulcers developed over the next 18 months (0/28 limbs). For several of these studies, the annual risk of developing a first DFU can only be approximated, and the results cannot be compared because information involving subject age, duration of diabetes, and duration of DPN are not uniformly known.

\section{Discussion}

Not all patients with DPN experience chronic pain when defined as being present for at least 12 months. ${ }^{51}$ Some reviews estimate a prevalence of chronic neuropathic pain in diabetes of $10 \%-20 \%$, and possibly as high as $40 \%-50 \%$ in those with DPN. ${ }^{52-54}$ It is important to distinguish between the mild to moderate discomfort commonly associated with DPN and the aching, deep burning, or electric/shooting foot 
pain characteristic of the painful DPN experienced by about $25 \%$ of DPN patients. ${ }^{1,55}$ The epidemiology of painful DPN is unclear, as most studies do not segregate patients by the presence or absence of pain. ${ }^{56}$ Similarly, among the studies we reviewed, descriptions of participants undergoing DNS were often limited and at times confusing. Few of the studies clearly distinguished between painful DPN, predominant small-fiber DPN, treatment-induced neuropathy, or diabetic polyradiculoneuropathy, and few distinguished between focal or multifocal painful compressive mononeuropathy and a diffusely painful DPN.

The confusing features of painful DPN undoubtedly reflect the time point at which it is studied. For example, there are reports of spontaneous resolution of severe pain associated with painful DPN within 10 months of onset in some patients, ${ }^{57}$ likely resulting in the 12 -month duration requirement used by some clinicians or investigators. Others have reported that mean pain scores remained essentially unchanged over nearly 5 years of follow-up. ${ }^{51}$ These scores, however, reflected a combination of worsening and improvement, with nearly one-third of cases experiencing substantially less pain at follow-up. Daousi et al reported that $23 \%$ of surviving patients diagnosed with painful DSP were pain free for at least 12 months when reassessed 5 years later. ${ }^{52}$ Although painful neuropathic symptoms often persist, a substantial proportion of patients with chronic painful DPN reported reduced symptoms and some became pain free despite deteriorating peripheral nerve function. ${ }^{58,59}$ Such observations make clear the importance of precise clinical criteria in clinical trials of painful DPN.

Few would argue with the concept of decompressing a nerve mechanically injured at a site of focal compression. The distinction between surgical decompression of nerves entrapped at known sites of localized compression vs DNS at sites not known to be entrapped to treat DPN is particularly relevant, but not fully clarified in many studies. ${ }^{60}$ The distribution of pain has been proposed as one strategy to determine who may be an ideal candidate for surgery. This is the approach used by Liao et al in their 2014 paper. $^{28}$ Patients were divided into a "focal pain" group, defined as pain over "scattered" areas of the legs, feet, heels, or toes (presumably characteristic of multiple mononeuropathies), vs a "diffuse pain" group, wherein patients' pain involved the entirety of the lower limbs (characteristic of a painful DPN). This determination was made retrospectively and all patients were required to have a positive Tinel sign at a known potential site of entrapment. While both the focal and diffuse groups benefited from DNS, the focal pain group tended to have better outcomes. Presumably, a mechanism of double crush including focal compression of baseline injured, diabetic nerves underlies the more focally affected patients. The authors state that their differentiation between "focal" and "diffuse" patients was inspired by Vinik and Casellini in 2014. ${ }^{61}$ Interestingly, Vinik's article does not make a clear distinction between focal and diffuse phenotypes or provide any methodology for differentiating between these possibilities. Vinik did separate diabetic neuropathies into symmetric polyneuropathies (DPN) and focal/multifocal neuropathies, including diabetic amyotrophy. Medical and surgical clinicians would agree that patients with atypical forms of diabetic neuropathies would not be surgical candidates.

Clearly, great challenges exist in differentiating any sort of "focal" vs "diffuse" phenotype, and the question remains whether this impression might guide decision making regarding surgical intervention. It is possible that the patient descriptions simply differed, and that the underlying pathophysiology is the same in either case. Tinel's sign has been used to potentially differentiate between these possibilities, although even the "diffuse" patients in Liao's study had Tinel signs. Even so, the sign itself may be of limited utility, and despite widespread application, a positive Tinel sign has generally been discredited for such use. Datema et al examined the sensitivity and specificity of Tinel's sign in predicting compressive neuropathies at the fibular head, dorsum of the ankle, or tarsal tunnel. ${ }^{62}$ Among patients with coexisting polyneuropathy, the sensitivity of a Tinel sign ranged from $0 \%$ to $20 \%$ and the specificity ranged from $73 \%$ to $91 \%$. A positive or negative Tinel sign has been shown to be of little use in the setting of common upper extremity compressive neuropathies such as carpal tunnel syndrome (CTS), ${ }^{63}$ and clinical screening procedures including Tinel sign showed poor or no agreement with CTS case definitions, with kappa values ranging between 0.00 and $0.18 .{ }^{64}$ Clinicians should be skeptical that this sign reliably indicates an ongoing "double crush" in support of surgery. Instead, a Tinel sign and a more focal pattern of pain may support more thorough electrodiagnostic testing and perhaps structural imaging of a site in question.

Ignoring the descriptive difficulties associated with the different types of painful DPN and patient selection, the observational pain results following DNS were uniformly favorable, with a robust effect size beginning immediately post-DNS and extending over several years. There were questions involving interpretation of pain relief in trials where subjects with unilateral and bilateral DNS were comingled, but all studies reported significant and relatively persistent pain reduction. As early as 2004 , DNS was said to 
change the natural history of DPN, representing a potential paradigm shift in health care administration and introducing an opportunity for cost savings. ${ }^{65}$ Yet, such conclusions may have been premature, with the greatest support coming from those observational studies having the highest risk of bias.

Only two studies performed DNS on one limb and used the contralateral limb as a control. The unblinded trial of Macaré van Maurik et al identified significant pain relief in the DNS leg at 3, 6, and 12 months post-DNS. ${ }^{66}$ The magnitude of pain relief was less than described in the other observational trials (effect size $50 \%-69 \%$ of the combined remaining studies at the three intervals), something attributed to differences in DPN severity ${ }^{66}$ They also observed pain relief in the non-operated control leg, albeit significantly less than the relief observed in the DNS leg (effect size of about one-third the size of the DNS leg). Rozen et al performed the only double-blind randomized-controlled trial in which some participants underwent sham surgery on one of their legs. The sham surgery leg was treated identically to the DNS leg aside from not undergoing a decompression release or neurolysis. ${ }^{32}$ Rozen et al recorded pain differently than the other observational studies (Likert vs VAS scale). In addition, the mean baseline pain was greater than that observed in the Macaré van Maurik trial, a conclusion based on the reduction in pain levels reported by Rozen et al. The values in pain reduction were substantially large as to suggest high baseline pain (data not available, full publication pending, S Rozen, University of Texas Southwestern Medical Center, personal communication, 2018). Nonetheless, the 12-month post-DNS pain relief reported by Rozen et al for the DNS leg was greater than that reported by Macaré van Maurik et al, but comparable to that reported by other observational studies. Surprisingly, the pain relief in the sham surgery leg at 12 months was comparable to the DNS leg and substantially greater than the pain relief observed in the control leg reported by Macaré van Maurik et al (effect sizes of 1.9 for the sham leg and 0.3 for the unblinded control leg). The results suggest that the sham operation produces pain relief. The mechanism is unclear, but may be in response to the tissue damage incurred during the sham procedure or by some other unexplained mechanism that did not have a similar effect on the control leg in the Macaré van Maurik study. Alternatively, and more likely, the sham surgery exposed the magnitude of the placebo effect associated with surgical procedures. Pain relief was significantly greater in the DNS leg compared with the sham surgery leg after 48 months, but the sham leg effect size of $\sim 2.5$ was notable. On the other hand, the absence of any significant change in their control group that underwent neither DNS nor sham surgery is similarly unexpected, given the natural history of painful DPN discussed earlier.

The improved pain perception in the control leg observed by Macaré van Maurik et al was potentially attributed to an influence from the operated leg, ${ }^{66}$ a phenomenon analogous to mirror image pain involving contralateral allodynia seen in some patients with post-traumatic neuropathic pain. ${ }^{67}$ The mirror image pain concept may involve the uncrossed spinothalamic tract cells, a small percentage of the spinothalamic cells at any level of the spinal cord. However, pain is not perceived bilaterally or contralaterally via the ipsilateral pathway, unless there is damage to the crossed spinothalamic fibers, as in the postcordotomy syndrome. ${ }^{68,69}$ To achieve bilateral analgesia from a unilateral intervention in these patients, a unilateral nociceptive input would have to be perceived bilaterally, so that the analgesia is likewise perceived bilaterally. Aside from posttraumatic neuropathic pain, there is little evidence that patients with neuropathic pain of peripheral origin perceive pain bilaterally from a unilateral source. There are experimental models showing increased levels of interleukin 10 (IL-10) in bilateral dorsal root ganglia after a unilateral nerve or spinal root constriction injury. ${ }^{70} \mathrm{IL}-10$ is an anti-inflammatory cytokine produced by immune cells that attenuate neuropathic pain induced by a chronic constrictive nerve injury. The signaling mechanisms responsible for alterations in the contralateral dorsal root ganglia are unclear, but similar bilateral results were observed after a sham operation in which nerves were exposed but no nerve ligature was applied. The authors proposed that tissue damage associated with a sham operation was sufficient to upregulate IL-10. No pain-related behavioral data were included to relate to the observations. Others have shown that administration of IL-10 at the site of a chronic constrictive nerve injury produced a brief and modest downregulation of the inflammatory response and the resulting thermal hyperalgesia. ${ }^{71}$ The evidence suggests that IL-10 is triggered in response to tissue injury (among other proinflammatory processes), but there is little evidence to consider it an explanation for bilateral pain relief following unilateral DNS. Unlike referred pain or pain in one location inhibiting pain in another, both of which have known neurophysiological explanations, there is no established basis for "referred analgesia" as might be considered the phenomenon observed here.

The DNS literature includes little attention to the surgical placebo effect, but does at times indicate that the possibility cannot be ruled out without a control group with sham operations. ${ }^{72}$ Approval of new drugs used to treat neuropathic 
pain requires randomized, double-blind, placebo-controlled trials and long treatment durations for confirmatory trials. Similar rigorous standards are rarely applied to surgical procedures. ${ }^{73}$ Particularly high levels of placebo response (eg, $50 \%$ decreases in VAS pain score) were found for $23 \%$ of participants in 57 clinical trials evaluating medications used to treat peripheral neuropathic pain, with $39 \%$ of participants receiving placebo experiencing a $30 \%$ reduction in neuropathic pain. ${ }^{74}$ In a New England Journal of Medicine editorial, Redberg described the ethics of performing a sham surgical procedure as involving a balance between the risk of sham surgery and the risk of mistakenly believing a procedure is useful because of a placebo effect, thereby subjecting thousands or millions of patients to a useless procedure. ${ }^{73}$ The magnitude of the surgical placebo effect has been reported to be about the same as for other placebo responses (ie, about $35 \%$ ), but of longer duration. ${ }^{75}$ The magnitude of placebo analgesia is substantial, having an effect size of $0.98-1.14$, about five times larger than observed in placebo control studies. ${ }^{76}$ In general, the strongest predictor of a placebo response is the subjectivity of the outcome, typically showing a pooled placebo effect exceeding $0.60 .{ }^{77} \mathrm{~A}$ recent study designed to assess the quantity and quality of randomized, sham-controlled studies of surgery found that the effect size did not differ significantly between surgery vs sham surgery for pain-related conditions. ${ }^{78}$ The authors concluded that the nonspecific effects of surgery are generally large, particularly in the area of pain-related conditions, where more evidence is needed from randomized placebo-controlled trials.

Presumably, several of the secondary objective measures are influenced by a placebo effect to a lesser extent than subjective pain perception; even so, many evaluations showed a beneficial effect similar to that observed for pain reduction. Measures of 2PD and touch-pressure included in several studies showed variable results, not only in methodology but also in outcome. Neither study that included a contralateral limb control reported a favorable improvement. ${ }^{33,34}$ The largest study that utilized 2PD showed a dramatic improvement in 2PD recorded from the pulp of the great and small toes 24 months post-DNS, with an effect size of nearly 7.0 and mean 2PD values presumably in the normal range for their technique. ${ }^{28}$ However, 2PD is a cortical sensation not generally considered sensitive for detecting DPN and is neither routinely included in the clinical evaluation of DPN nor mentioned in the Toronto Clinical Scoring System ${ }^{79}$ cited by Liao et al. ${ }^{28}$

NCSs represent a diagnostic gold standard used to identify the electrophysiological features of diabetic neuropathies, including DPN and focal entrapment mononeuropathies.
Surprisingly, a minority of studies described specifics of the NCS evaluation aside from mentioning global summary results (eg, neuropathy with or without superimposed nerve compression). Some studies made no mention of NCS results, indicating only their availability, whereas others were dismissive of their utility, indicating that NCSs provided a lack of significant information, with no consistent relationship with localized symptoms and a lack of pre- and post-DNS variation. ${ }^{38}$ It is true that NCS results may be of limited value at times, especially in cases of severe DPN when responses may be absent. It is also true that NCSs may be demanding, requiring careful attention to technical details such as limb temperature, stimulation sites, and distance measurements. Nonetheless, NCS results showed an overall beneficial effect of DNS, although the only study using a contralateral limb control showed negative results. Ignoring for a moment the variable findings, the NCS results reported were frequently not those relevant to focal entrapment. Specifically, only Macaré van Maurik et al reported motor and sensory response amplitudes (sensitive indicators of axonal loss) and distal latencies across potential entrapment sites (sensitive indicators of focal compression). Both measures showed deterioration post-DNS. Conversely, most studies reported only CVs, which, in the case of the tibial nerve, involved conduction in the nerve segment proximal to the site of potential entrapment. Common peroneal CVs measured across the fibular head and, therefore, including the site of potential compression would be most appropriate, and the common peroneal $\mathrm{CV}$ measures showed the largest pre- vs post-DNS effect size. However, most studies reported peroneal CV from above the fibular head to the ankle, not just across the site of potential compression at the knee. The substantial improvement noted in tibial and peroneal CVs relative to the sural CV supports a beneficial effect of DNS. Most would have considered the sural CV to represent a positive control, as this nerve was neither decompressed nor entrapped. However, the sural $\mathrm{CV}$ also showed improvement post-DNS, albeit to a lesser extent, a phenomenon which goes unexplained. Whether the improved sural CV post-DNS represents some unidentified factor such as increased near-nerve temperature due to increased blood flow or changes in sympathetic tone is unknown, but deserving of study explication.

An additional question remains of how the NCS results are to be interpreted. It is known that the conduction slowing across entrapped sites such as the carpal tunnel in patients with mild DPN is not a surrogate for pain, as the majority of these patients are not symptomatic for CTS. For example, in one study, over $23 \%$ of 414 participants fulfilling the criteria 
for a mild DPN also fulfilled NCS criteria for a median mononeuropathy at the wrist, whereas few were symptomatic for a CTS and only one $(0.2 \%)$ underwent CTS-release surgery on the studied nerve during the 18-month follow-up period. ${ }^{80}$ The reason for this increased prevalence of asymptomatic median mononeuropathy is unclear - possibly representing increased susceptibility of diabetic nerves to focal trauma or compression due to nerve swelling - but the implication visà-vis focal nerve entrapments in the foot is important. One interpretation is that focal NCS abnormalities are required but insufficient to justify DNS. Although the selective use of limb $\mathrm{CV}$ is a relatively insensitive measure of focal entrapment, the inconsistent yet generally favorable CV results post-DNS represent a physiological result that does not necessarily reflect a beneficial response in a clinically affected nerve. For example, increased CV associated with increased limb temperature is a normal physiological response and not equivalent to increased function, such as increased sensation. To date, the NCS results are not convincing, and favorable results from appropriately designed studies are currently unavailable.

The US imaging and microcirculation results are provocative, providing anatomical and physiological explanations for some of the unanswered questions relevant to painful DPN and to DNS. Identification of fusiform nerve swelling near compression sites provides a mechanical explanation for compressed nerves, as do the generally favorable results post-DNS, showing a significant decrease in nerve CSA and improved hemodynamics from baseline. Although the morphological and hemodynamic results including vascular resistance and flow volume were in the same direction, they appeared inconsistent across studies, likely reflecting differences in technique. Whether the technology at present has sufficient sensitivity and reproducibility is uncertain. These methods may improve over time, both technically and methodologically, as reporting protocols evolve. Similarly, the single study reporting transcutaneous oximetry results showed impressive improvement in oxygen partial pressures in the skin of the foot post-DNS, with most participants having values suggestive of tissue hypoxia improving to the normal range 1 month post-DNS and persisting at 18 months. There was little information about the extent of underlying diabetic peripheral vascular disease relative to neuropathic ischemia, but it is unclear if such information is measurable or relevant. Evaluation of microcirculation is important to understanding blood flow in the small blood vessels that supply the nerves and other tissues, and this is a developing area of research important to DPN. These microcirculation results suggest a possible explanation aside from improved sensation for the apparently reduced incidence of initial and recurrent neuropathic DFUs post-DNS relative to the contralateral foot. Ulceration is arguably resistant to the placebo effect, yet questions remain about influences such as unrecognized postoperative behaviors that differentially protect the DNS foot relative to the non-operated foot (eg, possible increased reliance on the non-operated leg, thereby increasing the likelihood of "injury"?). Nevertheless, the current favorable results of DNS vis-à-vis recurrent neuropathic DFUs, the relatively objective outcome measure, and the required surgical treatment make this condition a seemingly ideal candidate for a prospective RCT with sham surgery.

The present review confirms that the evidence does not support the use of DNS to treat painful DPN. Few would disagree that lack of evidence is not, in and of itself, evidence of ineffectiveness. Those who view DNS as a promising therapy for properly selected cases of painful DPN correctly note that unproven is not equivalent to unnecessary or ineffective and argue for patience while gathering better information. ${ }^{9}$ However, the lack of evidence is confounded by an overall lack of precision in defining cases of potential DNS candidates. The use of DNS to treat an unequivocally compressed nerve, with or without an underlying DPN, is indisputable, yet this literature blurs the boundary between treatment of a painful compressive mononeuropathy, confluent mononeuropathies, and a diffuse DPN. It is true that some studies emphasize focal symptoms and most studies utilize a positive Tinel sign as evidence of localized compression, despite evidence showing the limited clinical utility of this subjective measure. The use of electrodiagnosis, the existing gold standard for documenting a localized mononeuropathy, has been limited. Granted, it may be difficult to identify a focal nerve compression superimposed on a severe DPN, a problem highlighted by the difficulties identifying CTS superimposed on a DPN. ${ }^{81}$ The difficulty, however, is one of oversensitivity, and it is unlikely that a symptomatic compressive neuropathy would result in normal conduction across the site of compression. It also seems probable that focal abnormalities or asymmetric findings would occur frequently if localized nerve compression explained even a minority of cases of painful DPN. The credibility of NCS data was discredited at times when strikingly unequivocal results were obtained. At other times, seemingly inappropriate NCS measures were used, with reliance on $\mathrm{CV}$ measured in nerve segments above the site of a presumed compression, further confusing the distinction between nerve entrapment and diffuse DPN. Surprisingly, only a few studies addressed the effectiveness of decompression of an entrapped tibial nerve at the tarsal 
tunnel, the logical first step before expanding the procedure to multiple nerves at multiple potential entrapment sites.

Our analyses have limitations. Foremost, most of the studies included in our review were observational and used different eligibility criteria and outcome measures. Unlike gold-standard double-blind randomized controlled studies, observational studies have a high potential risk for bias as summarized in Table 2 for each study included in our analyses. The systematic error associated with such differences in risk of bias likely explains much of the variation in results observed between studies we reviewed. In addition, our intended metaanalysis was restricted because few studies using paired samples or repeated measures included the raw data or the paired sample correlations. This problem made it difficult to combine data or assess the significance of pre- and post-DNS changes and resulted in our use of pooled effect size estimates.

The difficulties involved in performing high-quality randomized trials with low risk of bias include, at least in part, the general reluctance to include sham procedures in the evaluation of surgical treatments. The only randomized double-blind trial that included sham surgery on one leg unexpectedly showed comparable pain relief in both the sham surgery and DNS legs (available in abstract only). ${ }^{32}$ The results most likely highlight the magnitude of the surgical placebo effect. The debate will presumably also include exploration of central mechanisms such as mirror image pain to explain the observation. Nonetheless, any explanation aside from a placebo effect will have to be reconciled with 1) prior observations that unilateral studies were difficult to perform because many participants wanted to extend their post-DNS improvement to the opposite side, 2) unblinded studies showing results favoring the DNS leg relative to the nonsurgical leg, and 3) analogous but more common situations such as a bilateral CTS, in which unilateral release has not been associated with bilateral pain relief.

The current emphasis on evidence-based medicine undoubtedly raises the bar when considering usual or novel surgical treatments. ${ }^{48}$ The concern that a promising, costsaving treatment for painful DPN is being denied to individuals without an effective alternative must be balanced with the risk and expense of performing unnecessary procedures, subjecting thousands or millions of patients to an ineffective surgical procedure. ${ }^{82}$

Our review supports the findings and recommendations from the AAN practice advisory published over a decade ago. ${ }^{83}$ That advisory supported the use of RCTs with blinded evaluations, something that has recently occurred with full results pending publication. The AAN statement also recom- mended the use of standard definitions of DPN, validated functional outcome measures with blinded independent evaluations, and distinguishing between entrapment neuropathy and peripheral polyneuropathy, issues that persist. In the treatment of pain, nonspecific effects of surgery are generally large. Evidence is needed from randomized, placebo-controlled trials to avoid the continuation of potentially ineffective treatments.

\section{Acknowledgments}

We thank Michael Clark, PhD, for statistical assistance and Kenneth L Casey, MD, for critical review of published manuscripts.

\section{Author contributions}

JWA designed the protocol. JWA and RJ selected initial publications suitable for review and extracted data. JWA analyzed the data. JWA and RJ made substantial contributions to analysis and interpretation of data, participated in drafting and critically revising the manuscript, and approved the final version for publication. JWA is the guarantor of the present manuscript and takes full responsibility for the integrity of the results.

\section{Disclosure}

JWA serves on the Epidemiology of Diabetes Interventions and Complications Study (EDIC) Continuing Follow-up (NeuroEDIC) and is a member of the EDIC Mortality and Morbidity Review Committee. He has received personal compensation for activities with Alnylam Pharmaceuticals, Eli Lilly \& Company, Lilly Research Laboratories, and Veristat, or by firms representing companies in litigation. These activities have been as a consultant, advisory board member, data monitoring committee member, mortality and morbidity review committee member, participating study investigator, or expert witness. None of the potential conflicts of interest relates directly to any of the material discussed in the current review. RJ reports no potential conflicts of interest.

\section{References}

1. Tesfaye S, Kempler P. Painful diabetic neuropathy. Diabetologia. 2005;48(5):805-807.

2. Albers JW, Pop-Busui R. Diabetic neuropathy: mechanisms, emerging treatments, and subtypes. Curr Neurol Neurosci Rep. 2014;14 473.1-473.11.

3. Therapeutics and Technology Assessment Subcommittee of the American Academy of Neurology, Chaudhry V, Stevens JC, Kincaid J, So YT. Practice Advisory: utility of surgical decompression for treatment of diabetic neuropathy: report of the Therapeutics and Technology Assessment Subcommittee of the American Academy of Neurology. Neurology. 2006;66(12):1805-1808. 
4. Dellon AL. Neurosurgical prevention of ulceration and amputation by decompression of lower extremity peripheral nerves in diabetic neuropathy: update 2006. Acta Neurochir Suppl. 2007;100:149-151.

5. Chaudhry V, Russell J, Belzberg A. Decompressive surgery of lower limbs for symmetrical diabetic peripheral neuropathy. Cochrane Database Syst Rev. 2008 (3):CD006152.

6. Baltodano PA, Basdag B, Bailey CR, et al. The positive effect of neurolysis on diabetic patients with compressed nerves of the lower extremities: a systematic review and meta-analysis. Plast Reconstr Surg Glob Open. 2013;1(4):e24.

7. Tu Y, Lineaweaver WC, Chen Z, Hu J, Mullins F, Zhang F. Surgical decompression in the treatment of diabetic peripheral neuropathy: a systematic review and meta-analysis. J Reconstr Microsurg. 2017;33(3):151-157.

8. Tannemaat MR, Datema M, van Dijk JG, Midha R, Malessy MJ. Decompressive surgery for diabetic neuropathy: waiting for incontrovertible proof. Neurosurgery. 2016;79(6):783-785.

9. Nickerson DS. Comments on a proposal to limit Medicare coverage of nerve decompression surgery (electronic citation); 20181-4. Available from: www dellon com $/ 8$ pdf.

10. Dekkers OM, Egger M, Altman DG, Vandenbroucke JP. Distinguishing case series from cohort studies. Ann Intern Med. 2012;156(1 Pt 1):t-40.

11. Harland NJ, Dawkin MJ, Martin D. Relative utility of a visual analogue scale vs. a six-point Likert scale in the measurement of global subject outcome in patients with low back pain receiving physiotherapy. Physiotherapy. 2015;101(1):50-54.

12. von Elm E, Altman DG, Egger M, et al. The Strengthening the Reporting of Observational Studies in Epidemiology (STROBE) statement: guidelines for reporting observational studies. Int J Surg. 2014;12(12):1495-1499.

13. Vandenbroucke JP, von Elm E, Altman DG, et al. Strengthening the Reporting of Observational Studies in Epidemiology (STROBE): explanation and elaboration. Epidemiology. 2007;18(6):805-835.

14. Baravarian B. Surgical decompression for painful diabetic peripheral nerve compression and neuropathy: a comprehensive approach to a potential surgical problem. Clin Podiatr Med Surg. 2006;23(3):621-635.

15. Olivo SA, Macedo LG, Gadotti IC, Fuentes J, Stanton T, Magee DJ. Scales to assess the quality of randomized controlled trials: a systematic review. Phys Ther. 2008;88(2):156-175.

16. Verhagen AP, de Vet HC, de Bie RA, et al. The Delphi list: a criteria list for quality assessment of randomized clinical trials for conducting systematic reviews developed by Delphi consensus. J Clin Epidemiol. 1998;51(12):1235-1241.

17. Higgins JP, Altman DG, Gøtzsche PC, et al. The Cochrane Collaboration's tool for assessing risk of bias in randomised trials. $B M J$. 2011;343:d5928.

18. Hedges LV, Olkin I. Statistical Methods for Meta-analysis. San Diego, CA: Academic Press; 1985.

19. Dunlap WP, Cortina JM, Vaslow JB, Burke MJ. Meta-analysis of experiments with matched groups or repeated measures designs. Psychol Methods. 1996;1(2):170-177.

20. Morris SB, Deshon RP. Combining effect size estimates in meta-analysis with repeated measures and independent-group designs. Psychol Methods. 2007:105-125.

21. Seidel J, Miller SD, Chow DL. Effect size calculations for the clinician: methods and comparability. Psychother Res. 2013:1-16.

22. Wiseheart M. Effect size calculator (Copyright ${ }^{\circ}$ ). Retrieved on 4 April 2018. Available from: http://www cognitiveflexibility org/effectsize/ 2013.

23. R Foundation for Statistical Computing. R: a language and environment for statistical computing. ISBN 3-900051-07-0; 2008. Available from: http://www R-project org.

24. Kelley K. Methods for the behavioral, educational, and social sciences: an R package. Behav Res Methods. 2007;39(4):979-984.

25. Dellon AL, Muse VL, Scott ND, et al. A positive Tinel sign as predictor of pain relief or sensory recovery after decompression of chronic tibial nerve compression in patients with diabetic neuropathy. $J$ Reconstr Microsurg. 2012;28(4):235-240.
26. Karagoz H, Yuksel F, Ulkur E, Celikoz B. Early and late results of nerve decompression procedures in diabetic neuropathy: a series from Turkiye. J Reconstr Microsurg. 2008;24(2):095-101.

27. Knobloch K, Gohritz G, Vogt PM. Surgical decompression of the lower leg in painful diabetic polyneuropathy. Oper Orthop Traumatol. 2012;24(1):74-79.

28. Liao C, Zhang W, Yang M, et al. Surgical decompression of painful diabetic peripheral neuropathy: the role of pain distribution. PLoS One. 2014;9(10):e109827-109828.

29. Rader AJ. Surgical decompression in lower-extremity diabetic peripheral neuropathy. J Am Podiatr Med Assoc. 2005;95(5):446-450.

30. Yang W, Guo Z, Yu Y, Xu J, Zhang L, Relief P. Pain relief and healthrelated quality-of-life improvement after microsurgical decompression of entrapped peripheral nerves in patients with painful diabetic peripheral neuropathy. J Foot Ankle Surg. 2016;55(6):1185-1189.

31. Macaré van Maurik JF, Schouten ME, Ten Katen I, Ten K, I, et al. Ultrasound findings after surgical decompression of the tarsal tunnel in patients with painful diabetic polyneuropathy: a prospective randomized study. Diabetes Care. 2014;37(3):767-772.

32. Rozen S, Wolfe G, Raskin P, et al. DNND (diabetic neuropathy nerve decompression) study: a controlled, randomized, double-blinded, prospective study on the role of surgical decompression of lower extremity nerves for the treatment of patients with symptomatic diabetic neuropathy with chronic nerve compression (Abstr). Diabetes. 2017;66:A27.

33. Macaré van Maurik JF, van Hal M, van Eijk RP, Kon M, Peters EJ. Value of surgical decompression of compressed nerves in the lower extremity in patients with painful diabetic neuropathy: a randomized controlled trial. Plast Reconstr Surg. 2014;134(2):325-332.

34. Aszmann OC, Kress KM, Dellon AL. Results of decompression of peripheral nerves in diabetics: a prospective, blinded study. Plast Reconstr Surg. 2000;106(4):816-822.

35. Crosby PM, Dellon AL. Comparison of two-point discrimination testing devices. Microsurgery. 1989;10(2):134-137.

36. Valdivia JM, Dellon AL, Weinand ME, Maloney CT. Surgical treatment of peripheral neuropathy: outcomes from 100 consecutive decompressions. J Am Podiatr Med Assoc. 2005;95(5):451-454.

37. Aszmann OC, Dellon AL, Lee DA. Decompression of multiple peripheral nerves in the treatment of diabetic neuropathy: a prospective, blinded study. Eur Surg. 2001;33(3):117-120.

38. Wieman TJ, Patel VG. Treatment of hyperesthetic neuropathic pain in diabetics. Decompression of the tarsal tunnel. Ann Surg. 1995;221(6):660-665.

39. Wood WA, Wood MA. Decompression of peripheral nerves for diabetic neuropathy in the lower extremity. J Foot Ankle Surg. 2003;42(5):268-275.

40. Zhang W, Zhong W, Yang M, et al. Evaluation of the clinical efficacy of multiple lower-extremity nerve decompression in diabetic peripheral neuropathy. Br J Neurosurg. 2013;27(6):795-799.

41. Dellon AL. Treatment of symptomatic diabetic neuropathy by surgical decompression of multiple peripheral nerves. Plast Reconstr Surg. 1992;89(4):689-697.

42. Macaré van Maurik JF, Franssen H, Millin DW, Peters EJ, Kon M. Nerve conduction studies after decompression in painful diabetic polyneuropathy. J Clin Neurophysiol. 2015;32(3):247-250.

43. Riazi S, Bril V, Perkins BA, et al. Can ultrasound of the tibial nerve detect diabetic peripheral neuropathy? A cross-sectional study. Diabetes Care. 2012;35(12):2575-2579.

44. Tekin F, Ağladioğlu K, Sürmeli M, et al. The ultrasonographic evaluation of hemodynamic changes in patients with diabetic polyneuropathy after tarsal tunnel decompression. Microsurgery. 2015;35(6): $457-462$.

45. Trignano E, Fallico N, Chen HC, et al. Evaluation of peripheral microcirculation improvement of foot after tarsal tunnel release in diabetic patients by transcutaneous oximetry. Microsurgery. 2016;36(1):37-41.

46. Nickerson DS. Low recurrence rate of diabetic foot ulcer after nerve decompression. J Am Podiatr Med Assoc. 2010;100(2):111-115. 
47. Lavery LA, Higgins KR, Lanctot DR, et al. Preventing diabetic foot ulcer recurrence in high-risk patients: use of temperature monitoring as a self-assessment tool. Diabetes Care. 2007;30(1):14-20.

48. Nickerson DS, Rader AJ. Low long-term risk of foot ulcer recurrence after nerve decompression in a diabetes neuropathy cohort. J Am Podiatr Med Assoc. 2013;103(5):380-386.

49. Nickerson DS, Rader AJ. Nerve decompression after diabetic foot ulceration may protect against recurrence: a 3-year controlled, prospective analysis. J Am Podiatr Med Assoc. 2014;104(1):66-70.

50. Aszmann O, Tassler PL, Dellon AL. Changing the natural history of diabetic neuropathy: incidence of ulcer/amputation in the contralateral limb of patients with a unilateral nerve decompression procedure. Ann Plast Surg. 2004;53(6):517-522.

51. Boulton AJ, Armstrong WD, Scarpello JH, Ward JD. The natural history of painful diabetic neuropathy - a 4-year study. Postgrad Med J. 1983;59(695):556-559.

52. Daousi C, Benbow SJ, Woodward A, Macfarlane IA. The natural history of chronic painful peripheral neuropathy in a community diabetes population. Diabet Med. 2006;23(9):1021-1024.

53. Ziegler D, Rathmann W, Dickhaus T, Meisinger C, Mielck A, KORA Study Group. Neuropathic pain in diabetes, prediabetes and normal glucose tolerance: the MONICA/KORA Augsburg Surveys S2 and S3. Pain Med. 2009;10(2):393-400.

54. Veves A, Backonja M, Malik RA. Painful diabetic neuropathy: epidemiology, natural history, early diagnosis, and treatment options. Pain Med. 2008;9(6):660-674.

55. Russell JW, Zilliox LA. Diabetic neuropathies. Continuum (Minneapp Minn). 2014;20(5):1226-1240.

56. Didangelos T, Doupis J, Veves A. Painful diabetic neuropathy: clinical aspects. Handb Clin Neurol. 2014;126:53-61.

57. Archer AG, Watkins PJ, Thomas PK, Sharma AK, Payan J. The natural history of acute painful neuropathy in diabetes mellitus. J Neurol Neurosurg Psychiatry. 1983;46(6):491-499.

58. Benbow SJ, Chan AW, Bowsher D, Macfarlane IA, Williams G. A prospective study of painful symptoms, small-fibre function and peripheral vascular disease in chronic painful diabetic neuropathy. Diabet Med. 1994;11(1):17-21.

59. Benbow SJ, Cossins L, Macfarlane IA. Painful diabetic neuropathy. Diabet Med. 1999;16(8):632-644.

60. Dyck PJ. Practice advisory: utility of surgical decompression for treatment of diabetic neuropathy: report of the Therapeutics and Technology Assessment Subcommittee of the American Academy of Neurology. Neurology. 2007;68(10):796.

61. Vinik AI, Casellini CM. Guidelines in the management of diabetic nerve pain: clinical utility of pregabalin. Diabetes Metab Syndr Obes. 2013;6:57-78.

62. Datema M, Hoitsma E, Roon KI, et al. The Tinel sign has no diagnostic value for nerve entrapment or neuropathy in the legs. Muscle Nerve. 2016;54(1):25-30.

63. D'Arcy CA, Mcgee S. The rational clinical examination. Does this patient have carpal tunnel syndrome? JAMA. 2000;283(23):3110-3117.

64. Homan MM, Franzblau A, Werner RA, Albers JW, Armstrong TJ, Bromberg MB. Agreement between symptom surveys, physical examination procedures and electrodiagnostic findings for the carpal tunnel syndrome. Scand J Work Environ Health. 1999;25(2):115-124.

65. Aszmann O, Tassler PL, Dellon AL. Changing the natural history of diabetic neuropathy: incidence of ulcer/amputation in the contralateral limb of patients with a unilateral nerve decompression procedure. Ann Plast Surg. 2004;53(6):517-522.

66. Macaré van Maurik JF, Ter Horst B, van Hal M, Kon M, Peters EJ. Effect of surgical decompression of nerves in the lower extremity in patients with painful diabetic polyneuropathy on stability: a randomized controlled trial. Clin Rehabil. 2015;29(10):994-1001.
67. Huang D, Yu B. The mirror-image pain: an unclered phenomenon and its possible mechanism. Neurosci Biobehav Rev. 2010;34(4):528-532.

68. Kanpolat Y, Ugur HC, Ayten M, Elhan AH. Computed tomographyguided percutaneous cordotomy for intractable pain in malignancy. Neurosurgery. 2009;64(3 Suppl):ons187-ons194.

69. Collins KL, Taren JA, Patil PG. Four-decade maintenance of analgesia with percutaneous cordotomy. Stereotact Funct Neurosurg. 2012;90(4):266-272.

70. Jancalek R, Svizenska I, Klusakova I, Dubovy P. Bilateral changes of IL-10 protein in lumbar and cervical dorsal root ganglia following proximal and distal chronic constriction injury of peripheral nerve. Neurosci Lett. 2011;501(2):86-91.

71. Wagner R, Janjigian M, Myers RR. Anti-inflammatory interleukin-10 therapy in CCI neuropathy decreases thermal hyperalgesia, macrophage recruitment, and endoneurial TNF-alpha expression. Pain. 1998;74(1):35-42.

72. Hollis Caffee H, Caffee HH. Treatment of diabetic neuropathy by decompression of the posterior tibial nerve. Plast Reconstr Surg 2000;106(4):813-815.

73. Redberg RF. Sham controls in medical device trials. $N$ Engl J Med Overseas Ed. 2014;371(10):892-893.

74. Arakawa A, Kaneko M, Narukawa M. An investigation of factors contributing to higher levels of placebo response in clinical trials in neuropathic pain: a systematic review and meta-analysis. Clin Drug Investig. 2015;35(2):67-81.

75. Johnson AG. Surgery as a placebo. Lancet. 1994;344(8930):1140-1142.

76. Vase L, Petersen GL, Riley JL, Price DD. Factors contributing to large analgesic effects in placebo mechanism studies conducted between 2002 and 2007. Pain. 2009;145(1-2):36-44.

77. Wartolowska KA, Feakins BG, Collins GS, et al. The magnitude and temporal changes of response in the placebo arm of surgical randomized controlled trials: a systematic review and meta-analysis. Trials. 2016;17(1):589.

78. Jonas WB, Crawford C, Colloca L, et al. To what extent are surgery and invasive procedures effective beyond a placebo response? A systematic review with meta-analysis of randomised, sham controlled trials. $B M J$ Open. 2015;5(12):e009655.

79. Bril V, Perkins BA. Validation of the Toronto Clinical Scoring System for diabetic polyneuropathy. Diabetes Care. 2002;25(11):2048-2052.

80. Albers JW, Brown MB, Sima AAF, Greene DA. Frequency of median mononeuropathy in patients with mild diabetic neuropathy in the early diabetes intervention trial (EDIT). Muscle Nerve. 1996;19(2):140-146.

81. Perkins BA, Olaleye D, Bril V. Carpal tunnel syndrome in patients with diabetic polyneuropathy. Diabetes Care. 2002;25(3):565-569.

82. Redberg RF. Sham controls in medical device trials. $N$ Engl J Med. 2014;371(10):892-893.

83. Chaudhry V, Stevens JC, Kincaid J, So YT. Practice Advisory: utility of surgical decompression for treatment of diabetic neuropathy: report of the Therapeutics and Technology Assessment Subcommittee of the American Academy of Neurology. Neurology. 2006;66(12):1805-1808.

84. Dellon AL, Muse VL, Nickerson DS, et al. Prevention of ulceration, amputation, and reduction of hospitalization: outcomes of a prospective multicenter trial of tibial neurolysis in patients with diabetic neuropathy. J Reconstr Microsurg. 2012;28(4):241-246.

85. Lee $\mathrm{CH}$, Dellon AL. Prognostic ability of Tinel sign in determining outcome for decompression surgery in diabetic and nondiabetic neuropathy. Ann Plast Surg. 2004;53(6):523-527.

86. Nickerson DS, Rader AJ. Low long-term risk of foot ulcer recurrence after nerve decompression in a diabetes neuropathy cohort. JAm Podiatr Med Assoc. 2013;103(5):380-386.

87. Zhang W, Li S, Zheng X. Evaluation of the clinical efficacy of multiple lower extremity nerve decompression in diabetic peripheral neuropathy. J Neurol Surg A Cent Eur Neurosurg. 2013;74(02):096-100. 


\section{Supplementary material}

\section{MEDLINE (Ovid) search strategy}

1. randomized.ab

2. placebo.ab

3. trial.ab

4. (diabetes mellitus or diabet\$).mp. $[\mathrm{mp}=$ title, abstract, original title, name of substance word, subject heading word, keyword heading word, protocol supplementary concept word, rare disease supplementary concept word, unique identifier, synonyms]

5. exp diabetic neuropathies/ or diabetic peripheral neuropathy.mp
6. diabetic polyneuropathy.mp

7. exp diabetic foot/

8. exp decompression, surgical/

9. *tarsal tunnel syndrome/su [surgery]

10. exp foot/su [surgery]

11. or $/ 1-3$

12. or $/ 6-7$

13. or $8-10$

14. 11 and 12 and 13
Diabetes, Metabolic Syndrome and Obesity: Targets and Therapy is an international, peer-reviewed open-access journal committed to the rapid publication of the latest laboratory and clinical findings in the fields of diabetes, metabolic syndrome and obesity research. Original research, review, case reports, hypothesis formation, expert opinion and commentaries are all considered for publication. The manuscript management system is completely online and includes a very quick and fair peer-review system, which is all easy to use. Visit http://www.dovepress.com/testimonials.php to read real quotes from published authors.

Submit your manuscript here: https://www.dovepress.com/diabetes-metabolic-syndrome-and-obesity-targets-and-therapy-journal 